\title{
AVALIAÇÃO DA DEFORMAÇÃO GERADA NOS COMPONENTES INTERMEDIÁRIOS DE PRÓTESE FIXA IMPLANTO-SUPORTADA COM DIFERENTES ALTURAS, COM A UTILIZAÇÃO DE EXTENSÔMETROS LINEARES ELÉTRICOS.
}

Valdey Suedam

Dissertação apresentada à Faculdade de Odontologia de Bauru, da Universidade de São Paulo, como parte dos requisitos para obtenção do título de Mestre em Odontologia, Área de Reabilitação Oral. (Edição Revisada) 


\section{AVALIAÇÃO DA DEFORMAÇÃO GERADA NOS COMPONENTES INTERMEDIÁRIOS DE PRÓTESE FIXA IMPLANTO-SUPORTADA COM DIFERENTES ALTURAS, COM A UTILIZAÇÃO DE EXTENSÔMETROS LINEARES ELÉTRICOS.}

Valdey Suedam

Dissertação apresentada à Faculdade de Odontologia de Bauru, da Universidade de São Paulo, como parte dos requisitos para obtenção do título de Mestre em Odontologia, Área de Reabilitação Oral. (Edição Revisada)

Orientador: Prof. Dr. José Henrique Rubo 


\begin{tabular}{|c|c|}
\hline \multirow{4}{*}{ S522a } & Suedam, Valdey \\
\hline & $\begin{array}{l}\text { Avaliação da deformação gerada nos componentes } \\
\text { intermediários de prótese fixa implanto-suportada com } \\
\text { diferentes alturas, com a utilização de extensômetros } \\
\text { lineares elétricos.-- Bauru, } 2005 \text {. }\end{array}$ \\
\hline & 79 p.: il.; $30 \mathrm{~cm}$ \\
\hline & $\begin{array}{l}\text { Dissertação (Mestrado) - Faculdade de Odontologia de } \\
\text { Bauru, USP. } \\
\text { Orientador: Prof. Dr. José Henrique Rubo }\end{array}$ \\
\hline
\end{tabular}

Autorizo, exclusivamente para fins acadêmicos e científicos, a reprodução total ou parcial desta dissertação por processos fotocopiadores e/ou meios eletrônicos:

Data: 10/10/2006

Assinatura do autor: 


\section{VALDEY SUEDAM}

Nascimento

1995-1998

2000-2002

2003-2005

Filiação
21 de janeiro de 1974

Barretos - SP

Calil Suedam

Neide Siqueira Suedam

Curso de Odontologia na Faculdade de Odontologia de Bauru da Universidade de São Paulo

Curso de Especialização em Prótese Dentária no Hospital de Reabilitação de Anomalias Craniofaciais de Bauru - USP

Curso de Mestrado em Odontologia, área de concentração Reabilitação Oral na Faculdade de Odontologia de Bauru - USP 
Dedico este trabalho a meus pais: Calil e Neide "in memorian"

Aos meus irmãos : Vera, Valter, Vânia, Vanderlei e Verônica E aos meus sobrinhos: Thiago, Vinicius, Guilherme e Laura Pelo incentivo, suporte, carinho e alegria.

Ao Alceu e a Inge Pelos conselhos, orientações e carinho.

A minha namorada: Ivy Kiemle Trindade Por todo amor, companheirismo e ajuda. 
Os meus sinceros agradecimentos:

Ao meu orientador: Prof José Henrique Rubo Pela amizade, disponibilidade e ensinamentos.

Aos Professores do Departamento de Prótese Pelos ensinamentos e orientações, que contribuíram para o meu crescimento profissional.

Aos meus colegas de mestrado: Érico, Estevan, Felipe, Jonas, Lucas, Lívia, Mariana, Mikaela, Patrícia, Kátia, Rodrigo e Tânia Pela amizade e companheirismo.

Ao engenheiro Márcio Pela dedicação e disponibilidade na realização dos experimentos desta dissertação, 


\section{SUMÁRIO}

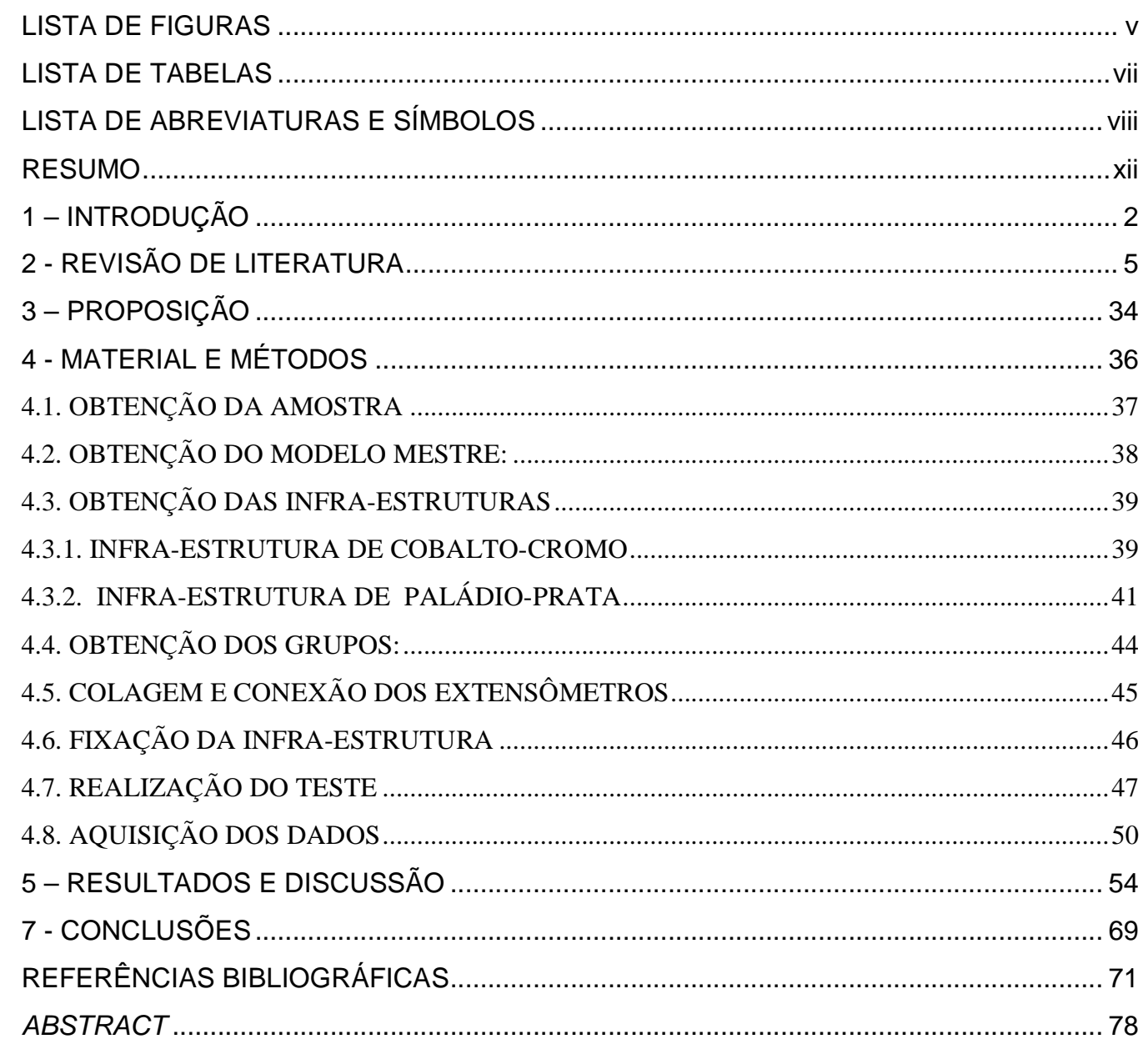


LISTA DE FIGURAS 


\section{LISTA DE FIGURAS}

Figura 4.1. Vista superior do modelo mestre com os análogos posicionados.........38

Figura 4.2. Vista dos cilindros fundidos em cobalto-cromo ..................................40

Figura 4.3. Vista inferior da infra estrutura de CoCr encerada ............................ 40

Figura 4.4. Vista superior da infra-estrutura de CoCr..........................................41

Figura 4.5. Vista inferioro da infra-estrutura de PdAg encerada......................... 42

Figura 4.6. Vista superior da infra-estrutura de PdAg ...................................... 42

Figura 4.7. Vista superior da placa de aquisição de dados ligada a um canal de extensometria .......................................................................... 46

Figura 4.8. Aplicação do torque de $10 \mathrm{Ncm}$ com o dispositivo de torque.................47

Figura 4.9. Aplicação da força estática de $100 \mathrm{~N}$ a $15 \mathrm{~mm}$ de distância do centro de

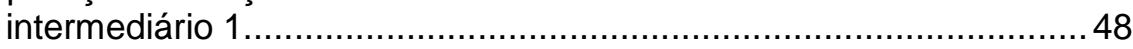

Figura 4.10. Desenho esquemático da disposição dos canais de aquisição $(C)$ e intermediários (I) ................................................................. 49

Figura 4.11. Fases das variações dos valores de deformação .............................52

Figura 5.1. Gráfico das médias de microdeformação captadas pelos canais de extensometria dos intermediários dos corpos de prova do grupo I........60

Figura 5.2. Gráfico das médias de microdeformação captadas pelos canais de extensometria dos intermediários dos corpos de prova do grupo II.......60

Figura 5.3. Gráfico das médias de microdeformação sofridas pelo corpo de prova I, apresentando a tendência a deformação da infra-estrutura de $\mathrm{CoCr}$, com intermediários de $4,0 \mathrm{~mm}$ de altura

Figura 5.4. Gráfico das médias de microdeformação sofridas pelo corpo de prova II, apresentando a tendência a deformação da infra-estrutura de $\mathrm{CoCr}$, com intermediários de $5,5 \mathrm{~mm}$ de altura

Figura 5.5. Gráfico das médias de microdeformação sofridas pelo corpo de prova III, apresentando a tendência a deformação da infra-estrutura de $\mathrm{CoCr}$, com intermediários de 7,0 mm de altura

Figura 5.6. Gráfico das médias de microdeformação sofridas pelo corpo de prova IV, apresentando a tendência a deformação da infra-estrutura de PdAg, com intermediários de 4,0 $\mathrm{mm}$ de altura 65

Figura 5.7. Gráfico das médias de microdeformação sofridas pelo corpo de prova $\mathrm{V}$, apresentando a tendência a deformação da infra-estrutura de $\mathrm{PdAg}$, com intermediários de $5,5 \mathrm{~mm}$ de altura

FIGURA 5.8. Gráfico das médias de microdeformação sofridas pelo corpo de prova VI, apresentando a tendência a deformação da infra-estrutura de PdAg, com intermediários de $7,0 \mathrm{~mm}$ de altura..... 
LISTA DE TABELAS 


\section{LISTA DE TABELAS}

Tabela 1. Especificações das ligas utilizadas segundo os fabricantes.

Tabela 2. Carga vertical estática de $100 \mathrm{~N}$, aplicada no corpo de prova I (intermediários de 4,0 $\mathrm{mm}$ de altura).

Tabela 3. - Carga vertical estática de $100 \mathrm{~N}$, aplicada no corpo de prova II (intermediários de $5,5 \mathrm{~mm}$ de altura) 55

Tabela 4. Carga vertical estática de $100 \mathrm{~N}$, aplicada no corpo de prova III (intermediários de 7,0 mm de altura)

Tabela 5. Carga vertical estática de $100 \mathrm{~N}$, aplicada no corpo de prova IV (intermediários de 4,0 $\mathrm{mm}$ de altura)....

Tabela 6. Carga vertical estática de $100 \mathrm{~N}$, aplicada no corpo de prova V (intermediários de 5,5 $\mathrm{mm}$ de altura)

Tabela 7. Carga vertical estática de $100 \mathrm{~N}$, aplicada no corpo de provaVI (intermediários de 7,0 $\mathrm{mm}$ de altura).... 


\section{LISTA DE ABREVIATURAS E SÍMBOLOS}

\begin{tabular}{ll} 
AgPd & paládio-prata \\
$\mathrm{CoCr}$ & cobalto-cromo \\
$\mathrm{Ga}$ & gálio \\
$\mathrm{W}$ & tungstênio \\
$\mathrm{C}$ & canal de extensômetria \\
$\mathrm{I}$ & intermediário \\
${ }^{\circ} \mathrm{C}$ & grau Celsius \\
$\mathrm{g}$ & gramas \\
$\mathrm{K}$ & grau Kelvin \\
$\mathrm{L}$ & comprimento inicial \\
$\Delta \mathrm{L}$ & variação do comprimento \\
$\mathrm{mm}$ & milímetros \\
$\mathrm{cm}{ }^{3}$ & centímetro cúbico \\
$\mathrm{Ncm}$ & Newton centímetro \\
$\mathrm{rpm}$ & rotações por minuto \\
$\varepsilon$ & tensão \\
$\mu \varepsilon$ & microstrains \\
$\mu \mathrm{m}$ & micrometros \\
$\mu$ & micro \\
$\mathrm{GPa}$ & giga pascal \\
\hline
\end{tabular}


Resumo 


\section{RESUMO}

Em prótese total fixa implanto-suportada as diferentes alturas dos intermediários traduzem-se em diferentes braços de alavanca aos quais os implantes são submetidos levando a um efeito de deformação dos componentes que até o momento é desconhecido. O objetivo deste trabalho foi verificar a deformação gerada em diferentes alturas de componentes intermediários de prótese total fixa mandibular implanto-suportada. Para isto foi utilizado um modelo mestre de forma circular confeccionado em aço comum (Aço 1010/20) com cinco perfurações onde foram adaptadas as réplicas de fixação de $3,75 \mathrm{~mm}$ de diâmetro, nas quais foram fixados os intermediários. $O$ trabalho apresentou dois grupos de três corpos de prova cada, divididos de acordo com o tipo de liga das infra-estruturas( $\mathrm{CoCr}$ ou $\mathrm{PdAg})$ e altura dos intermediários $(4,0 \mathrm{~mm}, 5,5 \mathrm{~mm}$ e $7,0 \mathrm{~mm})$, respectivamente. Foi aplicada uma força de $100 \mathrm{~N}$, em um ponto de referência pré-determinado na extremidade livre, a uma distância de $15 \mathrm{~mm}$ do centro da réplica de fixação terminal e realizadas leituras das deformações geradas na mesial e na distal de cada intermediário, com o uso de extensômetros lineares elétricos. Os resultados do estudo demonstraram que o aumento da deformação captada no intermediário adjacente ao cantilever é promovido pelo aumento da altura dos intermediários e também pela utilização de uma liga de alto módulo de elasticidade.

Palavras-chave: Prótese dentária fixada por implante. Biomecânica. Implante dentário. 
INTRODUÇÃO 


\section{1- INTRODUÇÃO}

A utilização de implantes osseointegrados de titânio para suportar próteses dentárias foi primeiramente descrita por Branemark e cols, em 1964, em um estudo com cães. A evolução dos estudos em osseointegração levou a utilização dos implantes de titânio em seres humanos, onde o primeiro tratamento se deu na "Branemark Gothenburg Clinic" em 1965. A aplicação inicial dos implantes osseointegrados foi baseada no tratamento de mandíbulas edêntulas com a utilização de uma prótese, denominada de protocolo, que recompõe toda a arcada inferior, parafusada a implantes osseointegrados $\mathrm{e}$ com extensões em cantilever para a distal. A substituição da prótese total convencional pela prótese total implanto suportada foi uma inovação que mudou os princípios básicos da prótese ${ }^{54}$.

O protocolo tradicional do sistema Brånemark para um paciente edentado mandibular consiste na colocação de 5 implantes entre os forames mentonianos, uma vez que a utilização de seis implantes fica bastante dificultada em algumas situações. O número de implantes colocados é geralmente reduzido para cinco, ou mesmo quatro, sem prejuízo aparente no índice de sucesso a longo prazo da restauração protética. (DAVIS; ZARB; $\mathrm{CHAO}^{3}$, em 1988) ${ }^{13}$.

Com a crescente utilização dos implantes osseointegrados de titânio para confecção de próteses dentárias, foram surgindo dúvidas sobre o comportamento mecânico desse tipo de prótese e observações sobre possíveis falhas que poderiam ocorrer com o sistema prótese/implante/osso. Havendo também a necessidade de se compreender a biomecânica da aplicação das forças mastigatórias e parafuncionais por todo este sistema e qual o efeito destas forças nos componentes das próteses e conseqüentemente no osso adjacente aos implantes osseointegrados.

O sucesso ou a falha das próteses sobre implante tem como fatores críticos a incidência e a transferência de estresses mecânicos sobre os 
implantes e destes para o tecido ósseo adjacente. É essencial que tanto o tecido ósseo como os implantes sejam submetidos somente ás forças aos quais estão aptos a suportar (SKALAK ${ }^{47}$, em 1983).

A sobrecarga mecânica pode acarretar falhas biológicas, ou seja, a falha do implante. Quando uma sobrecarga é aplicada em um implante osseointegrado o osso circunjacente a este sofre uma deformação (de 2000 a 3000 "microstrain"). Quando uma sobrecarga patológica ocorre (acima de 4000 "microstrain") o estresse e a tensão gerados excedem o limiar fisiológico tolerado pelo osso e ocorrem microfraturas na interface implante-osso. A aplicação de repetidas cargas pode levar a falha por fadiga da interface, diminuindo a densidade óssea periimplantar e levando à formação de defeitos ósseos do tipo crateras ${ }^{40}$.

As falhas tardias em implantes, após a instalação das próteses, estão correlacionadas com complicações biomecânicas. Os mecanismos relacionados com estas falhas ainda não são totalmente entendidos e a literatura a respeito das influências dos vários fatores biomecânicos é inconclusiva ${ }^{40}$.

A distribuição de forças entre os componentes do sistema prótese/implante/osso, a reação de cada parte componente deste sistema e a mensuração destas forças transmitidas são de fundamental importância para entendimento de todo o processo biomecânico de distribuição de cargas funcionais e parafuncionais. Sabe-se que o aumento da distância de aplicação da carga em relação ao centro do implante acarreta no aumento do braço de alavanca $^{42}$. O mesmo poderá ocorrer com 0 aumento da altura do intermediário, porém não se sabe ao certo qual a magnitude desta relação, sendo de fundamental importância, para o planejamento e execução do tratamento com prótese sobre implantes, a mensuração dos valores de tensão gerada nos componentes intermediários de prótese fixa implanto-suportada variando a altura dos intermediários. 
REVISÃO DE LITERATURA 


\section{2 - REVISÃO DA LITERATURA}

SKALAK ${ }^{47}$, em 1983 publicou um artigo que é considerado um dos primeiros trabalhos a enfocar a importância da biomecânica nas próteses sobre implantes. Afirmando que o sucesso ou a falha desse tipo de prótese tem como fatores críticos a incidência e a transferência de estresses mecânicos sobre os implantes e destes para o tecido ósseo adjacente. Sugerindo que tanto o tecido ósseo como os implantes deveriam ser submetidos somente a forças aos quais estariam aptos a receber. Salientando que a união rígida da prótese com 0 implante osseointegrado constitui uma unidade e, conseqüentemente, qualquer desalinhamento, entre a prótese fixa e os implantes, resultaria em um estresse interno da prótese, implantes e osso. Enfatizou que muito embora esses estresses possam não ser detectados visual ou clinicamente, podem ocasionar falhas, mesmo sem a presença de forças externas. E também salientou a importância da utilização de materiais que absorvam e distribuam melhor as cargas, como a resina acrílica dos dentes artificiais. Para o autor, esse conjunto permitiria uma infra-estrutura rígida com uma proteção externa para a absorção de impactos.

Em 1988, CHAO et $\mathrm{al}^{7}$ avaliaram a possibilidade da utilização das ligas de cobalto-cromo na confecção de infra-estrutura para próteses fixas implanto suportadas. Para a realização do trabalho utilizaram um modelomestre em liga de alumínio com cinco réplicas de intermediários "standard". Foi necessária a duplicação dos cilindros de ouro em resina acrílica para a confecção das infra-estruturas de cobalto-cromo, devido a diferença de temperatura de fundição desta liga, a qual não pôde ser fundida sobre a liga de ouro, enquanto que as infra-estruturas de paládio-prata foram confeccionadas sobre os cilindros de ouro. As infra-estruturas em cobalto-cromo apresentavam 2,5mm de largura e $4 \mathrm{~mm}$ de espessura, com cantilever de $22 \mathrm{~mm}$ de extensão. Para as ligas de paládio-prata, as infra-estruturras apresentaram-se com as mesmas medidas das infra-estruturas de cobalto-cromo, diferindo somente na largura, com $6 \mathrm{~mm}$. A precisão de adaptação da infra-estrutura ao intermediário foi analisada através de um microscópio óptico. Para verificar o comportamento 
das infra-estruturas ao receberem carga e a tensão gerada na superfície dos cantilevers, foram utilizados extensômetros lineares elétricos e análise de fotoelasticidade. Os extensômetros foram fixados no cantilever a uma distância de 7, 10 e $14 \mathrm{~mm}$ para distal do intermediário terminal. A infra-estrutura era parafusada no modelo-mestre e uma carga vertical de, no máximo, $20 \mathrm{Kg}$ era aplicada no cantilever, a uma distância de 14 e $20 \mathrm{~mm}$ para distal do intermediário terminal. Os dados obtidos com as ligas de cobalto-cromo foram comparados com os apresentados pelas ligas de prata-paládio. Os resultados demonstrados com as ligas de cobalto-cromo foram bastante promissores. A maioria das infra-estruturas de cobalto-cromo recebeu algum tipo de ajuste antes de se adaptarem passivamente aos intermediários, o que não foi necessário com as ligas de paládio-prata. A média de abertura marginal, entre infra-estrutura e intermediário, para as ligas de cobalto-cromo e prata-paládio foi, respectivamente, $26,4 \mu \mathrm{m}$ e $8 \mu \mathrm{m}$. Com relação à adaptação, as infraestruturas em cobalto-cromo foram inferiores às de paládio-prata. Os autores atribuíram a esses resultados a possibilidade de ter ocorrido uma maior contração de fundição da liga de cobalto-cromo e também ao menor grau de adaptação dos cilindros duplicados de resina acrílica em relação aos cilindros de ouro. Observaram que quanto mais próximo do intermediário terminal fosse aplicada a carga, menor a superfície de tensão no cantilever. A tensão gerada foi sempre maior na região mais próxima do intermediário terminal, independente do local de aplicação da carga (14 ou 20mm). Em relação às infra-estruturas de cobalto-cromo fundidas em monobloco, concluíram que estas mostraram adaptação aceitável (embora inferior às das infra-estruturas de paládio-prata) e por serem mais rígidas apresentaram a maior resistência à deformação do que as ligas de paládio-prata. O que possibilita a confecção de uma infra-estrutura com menor volume de metal, mais delicada, sendo essa uma grande vantagem em casos de espaço intra-oral limitado, sem diminuir a capacidade de absorver cargas.

Segundo RANGERT; JEMT; JÖRNEUS ${ }^{40}$, em 1989, o desenho das próteses e o posicionamento dos implantes têm importante influência no estresse que é transmitido para os implantes e para o tecido ósseo. Discutiram sobre os parâmetros biomecânicos que determinam as forças que incidem 
sobre os implantes e sugeriram princípios clínicos a serem adotados para minimizar problemas. Consideram que dois tipos principais de forças atuam sobre o implante: força axial e momento de torção. Sendo a força axial a mais favorável, distribuindo o estresse uniformemente através do implante; já o momento de torção transmite mais estresse ao implante e ao tecido ósseo subjacente. Salientaram que o ponto mais fraco do sistema é o parafuso de ouro, onde convenientemente as fraturas ocorrem, visto que é facilmente reposto. O afrouxamento é, geralmente, a causa mais comum de fratura do parafuso de ouro. Se este fraturar, apesar de estar bem apertado, isso pode indicar imprecisão da infra-estrutura protética. Quando a infra-estrutura está bem adaptada, com parafusos apertados com torque adequado e mesmo assim ocorrer a fratura, é aconselhável reavaliar a extensão do cantilever, o esquema oclusal e a posição dos implantes, pois o sistema pode estar sendo sobrecarregado.

Através de um estudo de análise bidimensional de elemento finito, WILLIAMS et al. ${ }^{60}$, em 1990, verificaram que uma infra-estrutura para prótese fixa implanto-suportada em liga de cobalto-cromo permitiu a distribuição mais uniforme de estresse ao longo de sua extensão em relação à liga de ouro. Apesar de ter um alto módulo de elasticidade, proporcionou uma transmissão de carga mais eficaz e duradoura. Os autores sugeriram a possibilidade de utilização da liga de cobalto-cromo em substituição às ligas de ouro em próteses sobre implantes.

Em 1990, ZARB; SCHMITT ${ }^{62}$ em um estudo longitudinal sobre a efetividade clínica de implantes osseointegrados descreveram os aspectos clínicos e complicações encontradas em 46 pacientes com próteses implantosuportadas. Em um período de 4 a 9 anos, os problemas e complicações encontrados foram observados e registrados em todas as etapas do tratamento. A fratura do parafuso de ouro foi a falha protética mais freqüente. Os autores sugeriram que esse problema poderia ser conseqüência de sobrecargas ou ausência de adaptação passiva da infra-estrutura. Afirmaram que a maioria dos problemas encontrados foram de natureza iatrogênica, embora alguns fossem inerentes ao próprio método. 
GOLL $^{18}$, em 1991, salientou que há uma grande dificuldade de se obter uma infra-estrutura com perfeita adaptação, já que todos os passos na confecção de uma prótese sobre implantes são críticos. O autor descreveu os erros e distorções que podem ocorrer durante a confecção da infra-estrutura de uma prótese total fixa implanto-suportada e ressaltou que, apesar disso, as etapas clínicas podem ser controladas através de procedimentos cuidadosos para se obter uma adaptação precisa da peça fundida. Recomendou que se utilizem, preferencialmente, componentes usinados, porque a adaptação é mais previsível em relação aos componentes plásticos fundíveis. A adaptação do cilindro de ouro e dos componentes de moldagem deve ser verificada na primeira consulta para assegurar que todos os componentes se adaptam adequadamente. Os intermediários devem ser recobertos com capas de proteção para evitar acúmulo de resíduos em sua superfície. Recomendou a fundição da infra-estrutura metálica em monobloco, justificando que a soldagem de 2 ou mais partes da infra-estrutura pode alterar as propriedades do metal e, além disso, a peça soldada não pode ser tratada termicamente. Também salientou que os materiais abrasivos utilizados no polimento podem prejudicar a superfície e, conseqüentemente, o assentamento e a adaptação da prótese.

Em 1991, JEMT ${ }^{27}$ apresentou um acompanhamento de 1 ano de 391 próteses parciais fixas sobre implantes, no qual relatou um sucesso de 99,5\% com o tratamento protético. Apesar de terem sido relatadas poucas complicações, a maioria ocorreu na maxila. As complicações encontradas com mais freqüência foram: problemas com a fala $(31,2 \%)$, mordida do lábio e bochecha $(6,6 \%)$, irritação causada pelo cantilever $(3,1 \%)$, problemas gengivais (fístula, hiperplasia, inflamação - 1,7\%), fratura da estrutura metálica $(0,8 \%)$. Não houve fratura de nenhum dos componentes. 271 próteses $(69,3 \%)$ apresentaram os parafusos estáveis no primeiro controle (após 1 semana), não havendo necessidade de apertamento. A instabilidade dos parafusos de ouro foi maior na maxila, sendo esta diferença estatisticamente significante. Salientou que quando o desenho da prótese é adequado, sendo esta rígida e com adaptação passiva, o risco de fratura dos componentes é baixo e a incidência dessa falha é maior no primeiro ano de função. Sugeriu um protocolo 
para análise de adaptação de próteses sobre implantes. Considerando uma prótese fixa suportada por 5 implantes, numerados de 1 a 5 da direita para a esquerda, a prótese deve ser posicionada e o parafuso 1 apertado totalmente. Através desse procedimento, observa-se a adaptação dos demais componentes. O procedimento deve ser repetido com outro parafuso distal (parafuso 5). Uma vez verificada a adaptação, prossegue-se com 0 apertamento dos parafusos, um de cada vez, iniciando-se pelo parafuso 2, depois na seqüência os parafusos $4,3,1$ e, por último, o parafuso 5 . Cada parafuso era apertado até sua primeira resistência, anotando-se a posição da chave e um máximo de $1 / 2$ volta $\left(180^{\circ}\right)$ deveria ser dado na chave para o aperto final. Outro método utilizado por JEMT, para avaliar a adaptação, foi a quantidade de voltas dadas durante o aperto dos parafusos. A prótese era considerada mal adaptada quando mais de meia volta era necessária para apertar completamente um parafuso, por este motivo, esta deveria ser separada e soldada.

Ainda em 1991, JEMT et $\mathrm{al}^{26}$. realizaram um estudo piloto in vivo comparando as forças desenvolvidas e transmitidas para os implantes, por uma overdenture e uma prótese fixa do tipo protocolo, utilizando um caso clínico com 6 implantes na maxila ocluindo contra dentes naturais, até prémolares. Confeccionaram 2 próteses, uma fixa do tipo protocolo e uma overdenture com sistema barra-clip ( 1 anterior e 2 nas extensões posteriores), ambas consideradas clinicamente adaptadas. Para medir as deformações, utilizaram 3 extensômetros fixos no intermediário direito mais distal. As cargas oclusais foram controladas através de um garfo medidor da força de mordida, sendo que o paciente ocluía no garfo em 5 posições diferentes: sobre o intermediário, anterior e posteriormente do mesmo lado e sobre o intermediário contra-lateral. Depois, o paciente mastigava um pedaço de parafina por 20 minutos, enquanto as forças transmitidas eram continuamente registradas. $A$ prótese fixa foi avaliada primeiro e, em seguida, o mesmo procedimento foi realizado com a overdenture. Os resultados indicaram que uma maior força de tensão foi desenvolvida durante a instalação da intra-estrutura da prótese fixa. Apesar das forças de compressão e tensão terem sido menores com a overdênture, quando submetida às forças oclusais, maiores forças laterais 
eram geradas no intermediário em questão. Mesmo em se tratando de um estudo com um único paciente, os autores consideraram que a força desenvolvida com o apertamento dos parafusos da prótese fixa poderia estar relacionada com a adaptação ou mesmo com a rigidez da barra. As forças tensionais e compressivas foram menores na overdenture, indicando que esta se move contra os implantes, distribuindo as forças também para a mucosa. Os resultados obtidos não podem ser generalizados, em virtude das limitações desse estudo.

Em 1992, MILLINGTON; LEUNG ${ }^{37}$ analisaram a possível relação entre o estresse gerado na superfície das infra-estruturas e a discrepância de adaptação em prótese fixa implanto-suportada, através de análise de fotoelasticidade. Um modelo experimental contendo quatro intermediários do Sistema Brånemark foi confeccionado e uma infra-estrutura em liga de ouro tipo IV foi fundida. Foram criadas, através de anéis metálicos, desadaptações verticais de 6 a $140 \mu \mathrm{m}$ em diferentes locais, entre o intermediário e o cilindro de ouro correspondente. Mesmo nas menores discrepâncias, de $6 \mu \mathrm{m}$, houve a indução de estresse. As maiores concentrações de estresse foram observadas nos intermediários mais centrais, e não nos terminais, independente do local da desadaptação.

Utilizando diferentes tipos de parafusos JORNÉUS, JEMT \& CARLSSON $^{28}$, em 1992, observaram a sua estabilidade através da aplicação de forças oclusais em coroas unitárias sobre implantes. A partir do cálculo das forças oclusais máximas (140 a 390N) observadas em pacientes com implantes unitários associadas a parâmetros geométricos, tentaram determinar a resistência de 4 tipos de parafuso: (1) de titânio com cabeça cônica com roscas do tipo 1; (2) de titânio com cabeça plana e roscas do tipo 1; (3) de titânio com cabeça plana e roscas do tipo 3 e (4) de ouro com cabeça plana. Os parafusos foram apertados em um implante de $10 \mathrm{~mm}$ com diferentes torques, entre 20 a $35 \mathrm{Ncm}$, através de um torquímetro. O torque necessário para causar a rotação do intermediário no hexágono do implante foi utilizado como medida da estabilidade da articulação parafusada. Cada tipo de parafuso foi testado antes e imediatamente após o apertamento 5 vezes, sendo que em 
cada teste novos componentes foram utilizados. O torque necessário para rotacionar o cilindro do intermediário no implante foi medido no sentido horário e anti-horário, sendo observado visualmente e ao se ouvir um estalo produzido pelo cilindro ao mudar de posição. Uma força de $70 \mathrm{~N}$ foi aplicada perpendicularmente ao longo-eixo do implante por 100 vezes e as amostras também foram submetidas a testes de carga cíclica. O afrouxamento é um problema potencial de todos os tipos de parafuso e o apertamento insuficiente e a geometria do parafuso são as causas principais, pois a força de tensão age a partir da cabeça para as roscas do parafuso. A pré-carga deve ser a maior possível para propiciar uma força de contato entre o intermediário e o implante. Quanto mais rígidos forem os materiais, mais estável é a união. Além disso, todos os materiais têm certo grau de elasticidade e o parafuso sofre um alongamento quando submetido a forças de tensão durante o apertamento. Quanto maior o alongamento, melhor a estabilidade final do parafuso. Os autores enfatizaram a importância do desenho da cabeça do parafuso na transmissão do torque máximo para a haste e roscas. Observaram a ocorrência de 2 mecanismos de afrouxamento do parafuso: por flexão e pelos efeitos de assentamento. Uma força de flexão acima da resistência do parafuso resulta em sua permanente deformação, causando a redução das forças de contato entre o intermediário e o implante. Conseqüentemente, o parafuso afrouxa com mais facilidade. Um outro mecanismo da perda do parafuso baseia-se no fato de que nenhuma superfície é completamente lisa. Mesmo superfícies cuidadosamente torneadas são rugosas quando vistas microscopicamente. Por isso, não entram em contato completamente. Quando a interface do parafuso é sujeita a cargas externas, ocorrem micromovimentos entre as superfícies, podendo causar um desgaste nas áreas de contato mas, ao mesmo tempo, aproximando mais as duas superfícies. Os autores destacaram que a qualidade do assentamento depende da aspereza inicial da superfície e da rigidez, bem como da magnitude das forcas incidentes. Superfícies rugosas e cargas externas mais pesadas aumentam o assentamento. Quando o efeito de assentamento completo é maior que o alongamento elástico do parafuso, 0 mesmo afrouxa porque não existem forças de contato para segurar o parafuso. Consideraram que os testes de carga utilizados representaram uma situação extrema, raramente ocorrendo em situações clínicas. Portanto, sugeriram que a 
utilização de parafusos de titânio possibilita uma boa margem de segurança na maioria das situações clínicas.

SHACKLETON et al. ${ }^{46}$, em 1992, verificaram a causa e a incidência dos problemas protéticos após a instalação de próteses fixas implanto-suportadas em um grupo de 25 pacientes tratados com prótese total fixa mandibular do Sistema Bränemark. A história clínica dos pacientes foi analisada para fossem obtidas informações sobre tratamentos adicionais, num período de acompanhamento de 10 a 70 meses. Os problemas mais freqüentes foram a fratura de componentes protéticos individuais ou da própria prótese $(34,2 \%)$; em seguida, o afrouxamento dos parafusos de ouro ou do intermediário ( $25,5 \%)$, problemas dos tecidos moles $(9,6 \%)$, queixas em relação à fonética $(8,2 \%)$ e queixas estéticas $(6,8 \%)$. A longo prazo, a análise dos resultados também mostrou que cantilevers de $15 \mathrm{~mm}$ ou menos são significativamente melhores que os mais extensos. De acordo com os resultados desse estudo, os autores concluiram que mais de $50 \%$ dos problemas protéticos são relacionados aos fatores de estresse que atuam sobre a prótese. E sugeriram que o comprimento do cantilever não deveria exceder $15 \mathrm{~mm}$ para minimizar os problemas mecânicos.

Em 1993, WEINBERG ${ }^{58}$ ressaltou as diferenças entre os aspectos biomecânicos da distribuição de forças em próteses implanto-suportadas e dento-suportadas. As diferenças na rigidez relativa das estruturas envolvidas, no meio de sustentação (osseointegração e ligamento periodontal), assim como no relacionamento complexo entre os componentes do sistema, as quais são responsáveis pela absorção e distribuição de forças. A distribuição de forças nas próteses dento-suportadas depende da estrutura rígida do dente e da prótese, contando ainda com a resiliência do ligamento periodontal. Nas próteses sobre implantes, a distribuição das forças depende do grau de deformação dos parafusos de retenção (do intermediário e de ouro), do intermediário, da própria prótese, do implante e do tecido ósseo, uma vez que a osseointegração não conta com a presença do ligamento periodontal. Portanto, nas próteses sobre implantes, a distribuição de forças é consideravelmente restrita. Enquanto o ligamento periodontal tem uma resiliência de 
aproximadamente $500 \mu \mathrm{m}$, a parte mais flexível do sistema de implantes, o osso, permite uma deformação máxima de $100 \mu \mathrm{m}$. Quando não se estabelece uma pré-carga suficiente e/ou uma adaptação adequada entre o intermediário e o cilindro de ouro, o parafuso de ouro pode sofrer deformação ou fratura. $O$ estabelecimento da pré-carga nessa interface, com o apertamento adequado do parafuso, com torque de $10 \mathrm{Ncm}$, pode minimizar a força de cisalhamento que sobre ele ocorre. Entretanto, quando existe uma desadaptação na interface intermediário / cilindro de ouro, a força de cisalhamento gerada no parafuso pode ser maior do que ele é capaz de suportar, podendo causar a fadiga do metal e até sua falha. Em uma prótese unitária, o afrouxamento ou falha do parafuso de ouro é facilmente detectável. Em uma prótese extensa, a falta de adaptação e a subseqüente falha do parafuso alteram a distribuição da força oclusal para outros pontos. Consequentemente, os outros implantes podem ser sobrecarregados, principalmente se essa falha ocorrer no implante distal de uma prótese com extensão em cantilever.

CLELLAND et al. ${ }^{8}$, em 1993, observaram a influência de intermediários angulados na geração de estresse próximo a um implante através de um estudo associando resina fotoelástica e uso de extensômetros. Implantes do Sistema Steri-Oss $(3.8 \mathrm{~mm} \times 10 \mathrm{~mm})$ foram incluídos numa resina

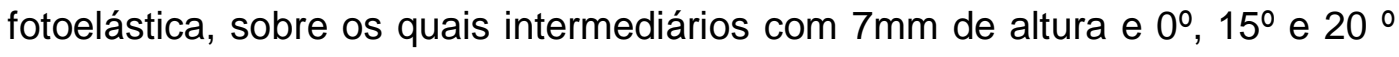
de angulação foram cimentados. Uma carga vertical de $178 \mathrm{~N}$ foi aplicada em cada intermediário. $\mathrm{O}$ estresse compressivo praticamente duplicou no lado do implante oposto à carga aplicada, à medida que a angulação dos intermediários aumentava de 0 a 20 graus. Apesar de haver um aumento estatisticamente significante do estresse, conforme o aumento da angulação do intermediário, os três ângulos de intermediários produziram estresses aparentemente dentro dos limites de adaptação fisiológica do tecido ósseo.

TAN et al. ${ }^{51}$, em 1993, avaliaram a distorção tridimensional em infra-estruturas confeccionadas em liga de paládio-prata fundida em monobloco sobre um modelo com cinco implantes. Compararam duas formas de infraestruturas: "L" e "U" (recomendada pelo grupo de Toronto). Consideraram o deslocamento dos cilindros de ouro das amostras em relação aos 
intermediários do modelo mestre quanto aos deslocamentos de translação e de rotação. Empregaram medidas de coordenadas com auxílio de uma máquina de medidas de coordenadas acoplada ao programa de microcomputador AVAIL (Advanced Validator Interfacing Language), o qual armazenava e calculava os dados geométricos. Não encontraram diferenças entre as formas das infraestruturas. A localização dos cilindros no arco foi associada a deslocamentos de translação e rotação com direção e magnitude específicas. Pequenas distorções rotacionais promoveram fendas verticais amplas quando realizaram o teste de adaptação inicial com apertamento de um parafuso. Entretanto, tais distorções podem ser camufladas quando o torque de apertamento é dado nos parafusos, fazendo a infra-estrutura parecer adaptada, provocando tensões externas de pré-carga no sistema.

Em uma edição especial da "International Journal of Oral Maxillofacial Implants" publicada em 1994, a respeito de assuntos relacionados à adaptação de próteses sobre implantes, YANASE $^{61}$ discorreu sobre a opinião de vários autores, os quais relataram como realizavam o teste de adaptação da infra-estrutura de uma prótese total fixa. Segundo JEMT, a verificação da adaptação da infra-estrutura é um dos procedimentos mais críticos durante a confecção de uma prótese implanto-suportada, pois nenhuma fundição apresentará uma adaptação completamente passiva micrometricamente. Ele ressaltou que a adaptação deve ser observada em um nível clinicamente aceitável, onde pequenas interfaces ou fendas entre a peça fundida e os implantes, antes do aperto dos parafusos, podem ser aceitas. GULBRANSEN, por sua vez, ressaltou que as possíveis fontes de imperfeições inerentes aos procedimentos de confecção da prótese devem ser observadas, como os procedimentos de transferência, de inclusão e fundição, as propriedades das ligas e dos materiais de moldagem e, ainda, as características dos componentes de implantes utilizados. PAREL salientou que é impossível a obtenção de uma adaptação realmente passiva, apesar de se dispor de vários métodos para melhorar os procedimentos de fundição e da confecção da prótese como um todo. Sugeriu que a inspeção visual e o apertamento do parafuso são as melhores formas de se avaliar a adaptação, ao se apertar o parafuso mais distal de um lado e observar a adaptação do outro lado da peça. 
Esta técnica é facilmente realizada, tanto no laboratório como clinicamente, embora não seja possível ser observada quando a interface está localizada subgengivalmente. Neste caso, o autor recomenda observar a quantidade de voltas necessárias para apertar o parafuso e, caso um parafuso exigir mais voltas, pode indicar um desajuste vertical. Os autores ressaltaram, ainda, a necessidade de verificação da fidelidade do modelo obtido e consideraram esse procedimento fundamental para a obtenção de uma peça bem adaptada e para permitir a verificação da adaptação já no próprio modelo.

Através de análise fotoelástica, WASKEWICKZ; OSTROWSKI; PARKS $^{56}$, em 1994, discorreram a respeito da necessidade da obtenção de próteses com adaptação passiva. Compararam os tipos de estresse gerados ao redor de implantes durante o aperto dos parafusos de infra-estruturas com adaptação passiva e com desadaptação sobre os intermediários. Utilizaram um modelo fotoelástico simulando a curva da mandíbula, com 5 implantes Nobelpharma $(3,75 \mathrm{~mm} \times 10 \mathrm{~mm})$, numerados de 1 a 5 no sentido horário. Utilizaram intermediários convencionais de $4 \mathrm{~mm}$ (Nobelpharma), que receberam um torque de $20 \mathrm{Ncm}$ através de um torquímetro. Para a confecção da infra-estrutura em liga de ouro-paládio, foram utilizados cilindros de ouro de $3 \mathrm{~mm}$ (Nobelpharma), os quais foram posicionados sobre os intermediários, e seus parafusos receberam um torque de $10 \mathrm{Ncm}$. Em seguida, os cilindros foram unidos entre si com resina autopolimerizável para o enceramento da infra-estrutura. Os autores constataram uma adaptação inadequada após a fundição da peça, com ausência de contatos íntimos entre cilindros de ouro e intermediários. Essa peça sem adaptação passiva foi analisada fotoelasticamente ao ser parafusada em posição com um torque de $10 \mathrm{Ncm}$ através de três diferentes seqüências de aperto dos parafusos de ouro: (a) 1, 2, 3, 4, 5; (b) 5, 4, 3, 2, 1 e (c) 3, 2, 4, 1, 5. Após todas as análises, a peça foi seccionada entre cada intermediário e em seguida, submetida à soldagem com a finalidade de se obter uma infra-estrutura adaptada passivamente. Cada parafuso de ouro foi apertado com um torque de $10 \mathrm{Ncm}$ e as partes foram unidas com resina acrílica Duralay. $O$ aperto da infra-estrutura sem adaptação passiva promoveu uma concentração de estresse ao redor dos implantes, o que pôde ser observado através da presença de franjas no modelo fotoelástico. 
Quando a peça adaptada (após a solda) foi parafusada, não houve a produção de estresse nos implantes. A produção de estresse na peça sem adaptação passiva foi indiferente nas 3 seqüências de aperto testadas. Os implantes 1 e 5 (nas extremidades) mostraram uma maior concentração de franjas. A concentração de estresse foi maior no terço médio de cada implante e menor nos terços cervical e apical dos mesmos. Os autores recomendaram o seccionamento e soldagem das infra-estruturas de próteses fixas sobre implantes a fim de se obter uma adaptação o mais passiva possível, baseandose no fato de que é impossível prever a resposta biológica dos implantes em relação a uma força estática quando uma prótese sem adaptação passiva é parafusada.

Segundo CARLSSON; CARLSON ${ }^{5}$, em 1994, uma prótese com adaptação passiva significa que esta pode ser parafusada sem causar estresse ou tensão. Porém ressaltaram que não existe uma adaptação absolutamente passiva já que todo aperto de parafuso gera uma certa deformação da prótese e/ou do osso, induzindo algum estresse ao sistema. O estresse e tensão são a conseqüência de uma prótese mal adaptada e são fatores que afetam a longevidade dos componentes. Sugeriram duas formas de medir o grau de desadaptação de um sistema: medindo as forças introduzidas durante o aperto dos parafusos, ou através da medida de extensão da desadaptação por meio de um microscópio de medição. $O$ autor salientou que devido as características do Sistema Bränemark, uma desadaptação de $50 \mu \mathrm{m}$ não gera tensão ao sistema; já uma desadaptação angular de mesmo tamanho pode gerar um deslocamento angular no ápice do implante para aliviar a tensão gerada. A precisão de adaptação entre o intermediário do implante e o componente protético da infra-estrutura tem sido questionada como um fator significante na transferência do estresse, na biomecânica dos sistemas de implante, na ocorrência de complicações e resposta dos tecidos na interface biológica.

No ano de 1994, HULTERSTRÖM; NILSSON ${ }^{24}$ realizaram um estudo clínico com um acompanhamento de 3 anos, no qual 66 pacientes receberam próteses fixas sobre implantes com infra-estruturas confeccionadas em liga de cobalto-cromo. Por motivos econômicos, visaram buscar alternativas 
que substituíssem o ouro para a confecção de infra-estrutura para próteses fixas implanto-suportadas. Duas ligas de cobalto-cromo foram utilizadas: (1) Wironit (BEGO) e (2) Formula Super Cast (Williams Dental Service AB). Nas infra-estruturas, parte da face lingual, vestibular e proximais foram confeccionadas em cobalto-cromo, enquanto as outras partes foram confeccionadas em resina acrílica. Foram realizados três tipos de conexões entre a infra-estrutura e os cilindros de ouro: no grupo 1, os cilindros de ouro foram conectados à infra-estrutura através de resina acrílica autopolimerizável; no grupo 2, os cilindros de ouro foram parcialmente soldados à infra-estrutura, combinados com conexões em resina acrílica autopolimerizável e, no grupo 3 , os cilindros de ouro foram completamente soldados à infra-estrutura. As próteses foram avaliadas clinicamente por um período de 6 meses a 3 anos. Nenhuma complicação em relação aos materiais foi observada, assim como nenhuma reação tecidual. As infra-estruturas não apresentaram descoloração ou corrosão. Segundo os autores, das três técnicas apresentadas, a soldagem parcial, usada no Grupo 2, seria o método mais recomendado. Consideraram as ligas de cobalto-cromo um material conveniente para a confecção de infraestruturas de prótese fixa implanto-suportada por oferecerem uma combinação favorável de biocompatibilidade, resistência à corrosão, boa fusibilidade, baixo peso específico, alta rigidez e custo reduzido. Indicaram seu emprego principalmente nos casos de mandíbula totalmente edêntula, onde não há problemas estéticos.

SPIEKERMANN ${ }^{48}$, em 1995, em artigo sobre métodos de investigação e análise biomecânica em prótese sobre implantes, relatou que os principais métodos de estudo são: a análise do elemento finito, análise de birrefringência (fotoelasticidade), a mensuração de cargas in vivo e in vitro e estudos da resistência de união entre implante e tecido ósseo. Segundo o autor, a análise de elemento finito oferece uma maneira de calcular a distribuição e concentração de estresse e deformações dentro dos implantes e no tecido de suporte circunvizinho, através de uma estrutura bi ou tridimensional computadorizada em forma de grade. Entretanto, a descrição matemática da interface é problemática. A técnica de análise de birrefringência é realizada através de cargas aplicadas em implantes ancorados em modelos 
plásticos, utilizando uma luz monocromática polarizada. Como os implantes são muito largos em relação à espessura necessária para este procedimento, observa-se fenômenos de sobreposição, tornando esse método raramente aplicado nos dias atuais. Com a mensuração de cargas in vivo e in vitro podese obter dados mais precisos em relação às forças exercidas sobre implantes ou dentes e transferidas às estruturas de suporte. Experimentos in vivo são, entretanto, de difícil execução porque é complicado incorporar sensores apropriados (extensômetros) em aparatos intra-orais, tanto do ponto de vista técnico, como biológico. Por outro lado, estudos in vitro têm obtido resultados valiosos. Por fim, há ainda os estudos da resistência de união entre implante e tecido ósseo, os quais realizados através de testes de cisalhamento, tração e compressão. Os resultados desses estudos sofrem uma influência significativa das condições experimentais. Dessa forma, a relevância clínica dos dados acumulados, a partir de casos individuais, deve ser avaliada criticamente.

VAN ZYL et al. ${ }^{55}$, em 1995, através de uma análise tridimensional de elemento finito, verificaram a distribuição de estresse no tecido ósseo circundante aos implantes, os quais suportavam uma prótese total fixa com extremidade livre bilateral. Uma força estática vertical de $100 \mathrm{~N}$ era aplicada ao longo de toda a extensão dos cantilevers, a partir de $7 \mathrm{~mm}$ do implante terminal, até $25 \mathrm{~mm}$, em pontos localizados a cada $2 \mathrm{~mm}$. Os resultados deste estudo demonstraram que os estresses distribuídos nas áreas mesiais e distais dos implantes foram, consideravelmente, inferiores aos estresses transmitidos às porções vestibulares e linguais. Os autores concluíram que extensões em cantilever superiores a $15 \mathrm{~mm}$, podem propiciar uma maior produção de estresse na cortical lingual e, em menor grau, na cortical vestibular, o que poderia colocar em risco a integridade dos implantes.

BENZING; GALL; WEBER ${ }^{3}$, em 1995, compararam o estresse gerado no tecido ósseo utilizando dois tipos de materiais para a confecção da infra-estrutura e dois diferentes conceitos de próteses fixas implantosuportadas para a maxila, através de mensuração clínica com extensômetros e análise de elemento finito. Os autores avaliaram um posicionamento "concentrado" de 4 a 6 implantes nas regiões de pré-molar e dentes anteriores associado a uma infra-estrutura com extensão em cantilever e um 
posicionamento "espaçado" de 6 implantes nas regiões de tuberosidades, prémolares e anterior, associados a uma infra-estrutura sem extensão em cantilever. A rigidez da infra-estrutura teve influência na concentração de estresse gerado no tecido ósseo. Uma infra-estrutura com extensão em cantilever suportada por 6 implantes não reduziu o estresse no tecido ósseo, quando comparada com um suporte promovido por 4 implantes e com 0 mesmo comprimento da extremidade livre. Concluíram que o emprego de uma liga com baixo módulo de elasticidade, especialmente em próteses com extensão em cantilever, provoca um grande risco em causar sobrecarga mecânica nos implantes mais distais.

Em 1995, através de um estudo in vitro, PATTERSON et al. ${ }^{39}$ analisaram as forças e momentos de torção transmitidos através dos intermediários, a partir da prótese até os implantes. Compararam os resultados obtidos com análises teóricas. Observaram que os momentos de torção foram maiores nos intermediários adjacentes às extremidades livres, o que poderia levar a falhas do parafuso de ouro. A força máxima de compressão no intermediário adjacente ao da extremidade aumenta proporcionalmente com a extensão do cantilever apresentando, por outro lado, um efeito reduzido na força de tração axial nos intermediários localizados anteriormente. Os autores concluíram que os momentos de torção podem ter uma importância relevante em relação às falhas em próteses sobre implantes.

ISA; HOBKIRK ${ }^{24}$, em 1995, avaliaram in vitro os efeitos causados pelo aperto do parafuso de ouro na instalação de uma infra-estrutura de 5 elementos com diferentes graus de desajuste marginal. Utilizaram um modelo com 5 réplicas metálicas do Sistema Brånemark (Nobelpharma), com 10mm, dispostas linearmente em uma base metálica rígida. Dois extensômetros fixados longitudinalmente em cada intermediário foram utilizados para as análises do estresse gerado. Foram produzidos desajustes de 10, 30, 60 e $110 \mu \mathrm{m}$ nos implantes 1, 3 e 5, através de arruelas de aço inoxidável entre os intermediários e os cilindros de ouro. O parafuso do intermediário foi apertado com um torque de $20 \mathrm{Ncm}$ e o parafuso de ouro, com $10 \mathrm{Ncm}$. Baseando-se nos resultados obtidos, concluíram que o aperto do parafuso de ouro gerou grande 
estresse de compressão e tração nos intermediários, mesmo com uma infraestrutura com desajustes tão pequenos quanto $10 \mu \mathrm{m}$.

KANO et al. ${ }^{29}$, em 1995, avaliaram a adaptação de infraestruturas fundidas a partir do componente calcinável da 31 (Implant Inovations) comparada à adaptação obtida com o cilindro de ouro Nobelpharma. Os resultados obtidos foram de $117 \mu \mathrm{m}$ para o cilindro de ouro Nobelpharma, $132 \mu \mathrm{m}$ para a matriz plástica fundida em liga Pors-On 4 (Degussa Hülls), $135 \mu \mathrm{m}$ para a matriz plástica antes da fundição, $156 \mu \mathrm{m}$ para a matriz plástica fundida em liga de níquel-cromo e $224 \mu \mathrm{m}$ para a fundição com a liga Palliag $\mathrm{M}$ (Degussa Hülls).

Em 1995, MILLINGTON; LEUNG ${ }^{36}$ avaliaram a relação existente entre o tamanho e localização das desadaptações e a distribuição de forças na superfície de infra-estruturas sobre implantes. Com o uso da fotoelasticidade, observaram a adaptação individual de uma infra-estrutura confeccionada em liga de ouro do tipo IV, parafusada em 4 intermediários (A, B, C e D) sobre implantes. Discrepâncias verticais foram introduzidas em um intermediário colocando-se folhas metálicas nos outros 3 intermediários e apertando os parafusos com torque de $10 \mathrm{Ncm}$. Para estabelecer o tamanho da fenda, a altura da superfície superior da infra-estrutura sobre o local da fenda foi monitorado com um transdutor, antes e após a instalação das discrepâncias verticais. Os efeitos de 9 alturas de discrepância $(6,17,27,40,55,68,81$ e $104 \mu \mathrm{m})$ foram testados individualmente no intermediário mais distal (D) e no intermediário C. O nível de aumento do estresse com o aumento da fenda não foi proporcionalmente linear. A maior incidência de estresse foi evidenciada sobre os intermediários, indiferente do local da desadaptação. Entretanto, observaram que o nível de estresse mostrou um rápido aumento chegando a um platô com a fenda de $55 \mu \mathrm{m}$. Em fendas maiores que $55 \mu \mathrm{m}$, o parafuso de ouro não desenvolvia força suficiente para aproximar a infra-estrutura na união das partes da junção, ou seja, a pré-carga não era alcançada com o torque utilizado. O intermediário em que a discrepância era criada sofria um efeito significativo quanto à magnitude e direção da transmissão do estresse. Houve uma relação positiva entre o tamanho da desadaptação e a magnitude do 
estresse na infra-estrutura em discrepâncias verticais maiores que $104 \mu \mathrm{m}$ no intermediário mais externo e desadaptações maiores que $55 \mu \mathrm{m}$ no intermediário central. Os autores chegaram às seguintes conclusões:

- $\quad$ desadaptações mínimas de $6 \mu \mathrm{m}$ induziram estresses na infra-estrutura;

- para desadaptações localizadas no intermediário central, o maior

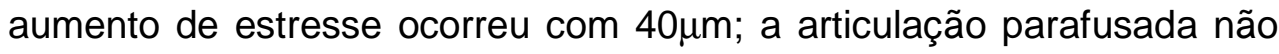
fechou a interface quando a desadaptação chegou em $55 \mu \mathrm{m}$.

- quando a desadaptação ocorria no intermediário mais distal, a superfície continuou a aumentar com até a maior discrepância testada $(104 \mu \mathrm{m})$.

- os níveis de estresse foram mais altos quando o erro de adaptação foi instalado no intermediário central, comparado com a mesma desadaptação no implante distal.

Em 1996, SERTGÖZ; GÜVENER ${ }^{44}$ investigaram a distribuição de estresse na interface implante / tecido ósseo através de uma análise tridimensional de elemento finito, onde foram utilizados três comprimentos diferentes de cantilevers e implantes. Foram criados modelos de simulação de uma prótese fixa implanto-suportada por seis implantes, embutidos em um modelo de osso mandibular (cortical e enponjoso) e com cantilevers posteriores bilaterais. Um total de nove modelos de simulação apresentavam três diferentes comprimentos de cantilevers ( 7,14 e $28 \mathrm{~mm}$ ) e três comprimentos de implantes (7, 15 e $20 \mathrm{~mm})$. Uma força de $75 \mathrm{~N}$ era aplicada, em direção perpendicular, na porção central e na região correspondente ao elemento mais posterior da extremidade livre. Uma força horizontal de $25 \mathrm{~N}$ era aplicada na superfície vestibular do elemento mais posterior do cantilever. As análises revelaram que os estresses máximos concentraram-se na interface tecido ósseo / implante mais distal, localizada no lado de aplicação da carga. O estresse de tração máximo foi observado nas regiões mesial e distal do tecido ósseo, quando uma carga vertical era aplicada, e nas regiões vestibular e lingual, sob carga horizontal. $\mathrm{O}$ aumento do comprimento do cantilever resultou 
na elevação dos valores de estresse na interface implante / tecido ósseo. No entanto, o comprimento do implante não teve efeito significativo na distribuição do estresse nesta interface.

CARR; BRUNSKI; HURLEY ${ }^{6}$, em 1996, mediram e compararam a pré-carga gerada com a utilização de cilindros de ouro, cilindros produzidos a partir de cilindro de ouro pré-fabricados, cilindros de plástico fundidos e cilindros de plástico fundidos após acabamento e polimento. Foram utilizados cilindros de ouro e de plástico compatíveis com o intermediário SDCA 004 Nobelbiocare (Nobelbiocare USA, Chicago). Para as fundições, foram utilizadas ligas de alta e baixa fusão para verificar a influência da temperatura na medida da pré-carga. Maior pré-carga foi desenvolvida nos cilindros pré-fabricados quando comparada com os confeccionados a partir de cilindros de plástico. A pré-carga no intermediário, cilindro de ouro e parafuso de ouro pode ser afetada pelos procedimentos de fundição. Os cilindros plásticos fundidos com a liga de baixa fusão produziram uma pré-carga significativamente maior que os fundidos com a liga de alta fusão. Houve um aumento significante na précarga dos cilindros de plástico, em relação aos efeitos do acabamento e polimento, enquanto o mesmo não foi observado nos cilindros metálicos. A escolha do tipo de cilindro, da liga metálica, do revestimento, das técnicas de acabamento e de polimento podem afetar a pré-carga resultante quando comparados com o cilindro pré-fabricado.

Preocupados com a biocompatibilidade das ligas metálicas utilizadas em próteses dentárias, KANSU; AYDIN ${ }^{30}$, em 1996, realizaram um experimento onde sete categorias de ligas odontológicas foram avaliadas por meio de uma análise histopatológica. O estudo incluiu ligas de alto e baixo conteúdo de ouro, à base de paládio, paládio-prata, níquel-cromo, cobaltocromo e ouro 22 quilates. Através da técnica de implantação subcutânea, discos fundidos de cada material foram implantados em ratos, por 15, 30 e 60 dias. A resposta tecidual mais severa foi verificada com as amostras em liga de níquel-cromo e a mais leve, com a liga de ouro de 22 quilates. Apesar de estar no grupo das ligas de metais básicos, a liga de cobalto-cromo apresentou respostas teciduais menos severas que a liga de níquel-cromo. Os autores 
concluíram que o uso de ligas que contenham níquel em sua composição deveria ser evitado.

PAPAVASILIOU; KAMPOSIORA; FELTON ${ }^{38}$ avaliaram a influência do grau de osseointegração no sucesso do tratamento com implantes em 1997. Determinaram, através de análise tridimensional de elemento finito, o nível de estresse na interface de implante com quatro graus de osseointegração (100, 75, 50 e 25\%) e cinco padrões de osseointegração (com localização alternada, somente cervical, apical, vestibular e lingual). Simularam uma coroa unitária submetida a carga axial e oblíqua de 10Mpa.Observaram que forças oblíquas oclusais elevaram o estresse na interface entre 5 a 20 vezes e estes foram sempre maiores na região de crista óssea. Menores níveis de estresse foram encontrados com a osseointegração na região cervical (crista óssea) associada à carga axial.

Através de um estudo de análise tridimensional de elemento finito, SERTGÖZ ${ }^{45}$, em 1997, simulou uma situação de prótese total fixa no arco mandibular, suportada por 6 implantes localizados na região anterior e com extensões em cantilever bilaterais de $16 \mathrm{~mm}$. A finalidade do trabalho era determinar a melhor combinação de materiais para a confecção da restauração protética quanto à infra-estrutura e ao material da superfície oclusal. Para tanto, utilizou resina acrílica, resina composta e porcelana como materiais para a superfície oclusal e ligas de ouro, prata-paládio, cobalto-cromo e titânio, como materiais para a infra-estrutura. Uma carga vertical total de $172 \mathrm{~N}$ foi empregada, o que correspondia à média de força durante a mastigação em uma prótese fixa implanto-suportada mandibular, com duas unidades em cantilever posterior bilaterais, ocluindo contra prótese total superior. Os pontos de aplicação estavam localizados no centro dos implantes terminais, no final das extremidades livres, à meia distância entre o centro dos implantes terminais e o final dos cantilevers e também em 4 pontos distribuídos na região anterior, entre os implantes distais. O estresse gerado no tecido ósseo ao redor dos implantes foi de pequena magnitude. Os estresses máximos foram bem inferiores aos limites de tração e compressão do osso cortical e medular. A utilização de materiais mais resilientes para a confecção da infra-estrutura não alterou o prognóstico biológico das próteses fixas implanto-suportadas, não 
havendo efeito deletério no tecido ósseo. A utilização de um material mais rígido para a confecção da infra-estrutura diminuiu o estresse gerado nos parafusos de ouro. Isso, provavelmente, significa que a alta resistência da infraestrutura à torção reduz o risco de sobrecarga mecânica nos parafusos de retenção, especialmente em infra-estruturas com extensões em cantilever. Sugeriram que a utilização de materiais mais rígidos poderia prevenir as falhas protéticas. Biomecanicamente, a infra-estrutura em liga de cobalto-cromo com a superfície oclusal em porcelana foi a melhor combinação de materiais encontrada.

CLELLAND; MEADE ${ }^{9}$, em 1997, mediram e compararam, através de extensômetros, a deformação gerada por infra-estruturas parafusadas e cimentadas e somente parafusadas. Utilizaram um modelo de resina fotoelástica com 5 implantes. Foram instalados 2 extensômetros do tipo roseta no modelo, posicionados no sentido vertical e paralelos aos implantes das 2 extremidades (direita e esquerda), a $2 \mathrm{~mm}$ de distância para vestibular, em uma altura correspondente à crista óssea. Foram confeccionadas 6 infra-estruturas de paládio-prata fundidas em monobloco, a partir da moldagem de transferência do modelo mestre, divididas em 2 grupos: cimentadas e parafusadas e parafusadas. Apenas uma foi considerada clinicamente desadaptada, sendo então seccionada e soldada para ser incluída no experimento. $O$ critério de aceitação clínica quanto à adaptação foi a avaliação do apertamento de apenas 1 parafuso de ouro em diferentes intermediários, sendo a peça considerada desadaptada quando nos demais intermediários desadaptações eram visualizadas. As infra-estruturas cimentadas com cimento resinoso dual, à base de Bis-GMA, foram previamente tratadas com jatos de óxido de alumínio e agente adesivo. Após a aplicação do cimento, os parafusos foram apertados seguindo-se a fotopolimerização. As amostras dos 2 grupos foram parafusadas com $10 \mathrm{Ncm}$, na seguinte ordem de intermediários: 3, 1, 5, 2, 4. A leitura dos extensômetros foi padronizada, sendo os dados armazenados a partir do apertamento inicial de cada infra-estrutura. Cada amostra foi submetida ao teste 3 vezes. Os resultados mostraram uma maior consistência no grupo 1, enquanto o grupo 2 mostrou uma maior variação das medidas fornecidas pelos 2 extensômetros. No grupo 2, a deformação foi 
consideravelmente maior no lado esquerdo, o que os autores atribuíram à seqüência de apertamento dos parafusos. Todos os parafusos foram parcialmente apertados manualmente e depois apertados com o torquímetro. Possivelmente, a maior pré-carga foi desenvolvida no primeiro parafuso apertado e, consequentemente, maior concentração de estresse nessa região do modelo. Os autores concluíram que infra-estruturas cimentadas e parafusadas minimizam a transmissão de estresse além de promoverem uma distribuição mais equilibrada.

HOBKIRK; HAVTHOULAS ${ }^{22}$, em 1998, observaram a possibilidade de influência da deflexão mandibular na transmissão de forças ao complexo tecido ósseo / implante / infra-estrutura. Utilizaram uma réplica de mandíbula humana edêntula, confeccionada em resina acrílica termopolimerizável, na qual foram posicionados verticalmente seis implantes do Sistema Bränemark (Nobel Biocare), de $3,75 \mathrm{~mm} \times 10 \mathrm{~mm}$, distribuídos entre os forames mentonianos. Dois extensômetros lineares foram fixados em cada intermediário convencional, de $5 \mathrm{~mm}$ de altura. Uma infra-estrutura padronizada na forma de barra foi fundida em liga de ouro tipo IV, com secção transversal de $6 \mathrm{~mm} \times 3,8 \mathrm{~mm}$ e $13 \mathrm{~mm}$ de extremidade livre em ambos os lados. Assim, poderia ser fixada em diferentes combinações de implantes e receber uma carga oclusal, de até $90 \mathrm{~N}$, em locais distintos, já pré-determinados por esferas metálicas. Os autores afirmaram que a rigidez da mandíbula está relacionada com as dimensões e propriedades do tecido ósseo e que quanto mais fina a cortical, maior a tendência de ocorrer deformação mandibular funcional. A configuração de suporte suspenso (simulando a naturalidade do suporte mandibular) demonstrou uma redução das forças de compressão e aumento das forças de tração, quando comparada com o suporte horizontal (na bancada), provavelmente em decorrência da deflexão mandibular. A utilização de um maior número de implantes contribuiu para um padrão mais amplo de distribuição de forças. No entanto, também produziu forças de tração maiores na região posterior, como resultado da má combinação das características de cisalhamento, da mandíbula e da infra-estrutura, e do efeito de alavanca do cantilever distal. 
TAYLOR, em $1998^{53}$, ao avaliar na literatura os tipos de problemas encontrados na implantodontia, observou que a desadaptação dos componentes protéticos tem um importante papel nas falhas mecânicas, salientando que a conexão do intermediário com o implante, que é mantida pelo parafuso, é uma região sujeita aos altos níveis de tensão por estar localizada perto da crista alveolar, sendo esta a região na qual são dissipadas as forças mastigatórias.

TAM et al. ${ }^{50}$, em 1999, propuseram-se a comparar a adaptação marginal e a capacidade de absorção de forças entre infra-estruturas fundidas em liga de cobalto-cromo e em liga de paládio-prata, sobre intermediários convencionais e estheticone. O sistema Preci-disc (Ceka) foi utilizado para a infra-estrutura cimentada. Um espaço de $0,1 \mathrm{~mm}$ foi estabelecido para a aplicação do agente cimentante entre os cilindros e a infra-estrutura, utilizando ainda o parafuso de ouro para fixar os componentes. Não foram observadas diferenças estatisticamente significante entre as infra-estruturas. Consideraram que o emprego de uma infra-estrutura em liga de cobalto-cromo cimentada pode obter adaptação tão precisa quanto infra-estruturas mais caras, fundidas em paládio-prata.

Em 1999, RUBO et al. ${ }^{41}$, avaliaram a distribuição de estresse entre os implantes através de um programa de análise de elemento finito, simulando uma prótese implanto-suportada numa mandíbula humana. Nesse modelo computadorizado, foram simuladas as seguintes variáveis: densidade do osso trabecular, comprimento dos intermediários e implantes, extensão do cantilever, número e arranjo dos implantes, grau de curvatura da mandíbula e a liga usada na confecção da infra-estrutura (prata-paládio e cobalto-cromo). Para simular a carga oclusal, empregaram uma carga de $100 \mathrm{~N}$. Observaram uma tendência de melhor distribuição do estresse entre os implantes e intermediários localizados em uma mandíbula mais estreita, ou seja, com um arranjo mais curvo, com uma extensão em cantilever menor, implantes longos e infra-estrutura mais rígida. A distribuição do estresse não foi influenciada pela densidade do osso trabecular. Quanto menor o número de implantes, maior estresse resultante sobre os intermediários. Os resultados mostraram ainda que a distribuição de estresse sobre a infra-estrutura foi independente da 
curvatura da mandíbula, sendo menor quando os implantes e intermediários eram mais longos e a liga utilizada, mais rígida.

KORIOTH; JOHANN ${ }^{31}$, em 1999, em estudo sobre a transmissão de estresse para o osso adjacente aos implantes variando a forma da infraestrutura, avaliaram a incidência de cargas laterais e oclusais em 5 formas de infra-estruturas e o estresse gerado no sistema, com a utilização da análise tridimensional de elemento finito. Em um modelo com 5 implantes simulando uma mandíbula edêntula e 2 materiais oclusais da infra-estrutura: metal e resina acrílica. O modelo foi submetido a simulação de cargas oclusais (vertical e lateral, somente vertical e somente lateral) bilateralmente. Os estresses máximos e mínimos foram calculados para cada intermediário e estes variaram significativamente tanto entre cada intermediário como entre as diferentes infraestruturas. Os intermediários mais distais desenvolveram os maiores níveis de estresse, geralmente compressivos, e forças de tensão ocorreram no intermediário vizinho. Os níveis mais baixos de estresse foram obtidos com a infra-estrutura de forma retangular, ao receber carga vertical. No entanto, os resultados mostraram que materiais com menor módulo de elasticidade parecem aumentar de maneira não uniforme a transmissão de cargas nos implantes. Os autores também observaram que uma infra-estrutura menos rígida pode reduzir a transmissão de estresse para os implantes mais anteriores, em relação aos demais, quando submetida a cargas oclusais posteriores. Os autores concluíram que os estresses desenvolvidos nos intermediários podem ser significativamente afetados pela forma da infraestrutura, pelas diferentes condições de incidência de carga e, em menor grau, pelas propriedades do material da infra-estrutura. Os resultados mostraram que a transmissão de estresse para os implantes anteriores foi menor quando o material com maior módulo de elasticidade foi utilizado.

HOLLWEG $^{32}$, em 2000, avaliou a passividade da adaptação de infra-estruturas simulando uma prótese total fixa mandibular sobre um modelo mestre com 5 implantes. Corpos de prova de paládio-prata e cobalto-cromo foram confeccionados e posicionados sobre um modelo mestre. Nas faces mesial e distal de cada intermediário foram fixados extensômetros lineares elétricos para capturar a deformação gerada durante o aperto dos parafusos de 
fixação. Embora tenha verificado a geração de tensões quando da aplicação de torque nos intermediários, observou que houve um nível de passividade semelhante entre as infra-estruturas fundidas em cobalto-cromo e pratapaládio. Sugeriu a utilização de ligas em cobalto-cromo para a realização de pesquisas clínicas.

JACQUES $^{25}$, em 2000, verificou a distribuição de estresse em componentes de prótese fixa implanto-suportada em função de ligas metálicas de cromo-cobalto e prata-paládio, através de um estudo no qual utilizou corpos de prova simulando infra-estruturas de prótese total fixa mandibular com cantilever sobre um modelo-mestre. Aplicou uma carga estática vertical de $100 \mathrm{~N}$ na extremidade livre, a uma distância de 10,15 e $20 \mathrm{~mm}$ para distal do intermediário terminal e mediu distribuição de forças através do uso de extensômetros. Os resultados demonstraram um padrão de distribuição de forças da liga cromo-cobalto em grandes extensões de cantilever semelhante à liga de prata-paládio com cantilever curto. Além disso, observou que o intermediário mais próximo do ponto de aplicação da carga foi o que registrou a maior deformação específica, independente do local de aplicação de força no cantilever e da liga utilizada. Concluindo que o emprego de uma liga de cobalto-cromo na confecção de infra-estruturas para prótese sobre implantes pode permitir braços de cantilever mais extensos.

Adaptação passiva, segundo SAHIN; ÇEHRELI ${ }^{43}$, em 2001, é sinônimo de uma "adaptação ideal". Teoricamente, uma infra-estrutura deveria proporcionar uma adaptação passiva, o que seria indução de tensão zero nos componentes de implantes e ao osso adjacente na ausência de cargas. Entretanto, uma adaptação realmente passiva é impossível de ser obtida. Os procedimentos clínicos e laboratoriais utilizados na confecção de infraestruturas são inadequados para propiciar tal adaptação. Complicações protéticas como afrouxamento e fratura dos parafusos, fratura do intermediário, da infra-estrutura e material de cobertura têm sido documentatas e relacionadas à desadaptação das infra-estruturas. Não há estudos clínicos longitudinais comprovando falhas nos implantes atribuídas especificamente à falta de adaptação da infra-estrutura. Uma adaptação marginal aceitável entre os componentes não significa a obtenção de uma adaptação passiva. Sugerem 
que o método ideal para se determinar a passividade de uma infra-estrutura seria a análise de tensão gerada em cada intermediário e/ou componente protético antes e após o apertamento dos parafusos e/ou cimentação da mesma. Tal procedimento só seria possível com a utilização de "strain gauges" (extensômetros). Cada passo na confecção de uma infra-estrutura influencia a adaptação final e, segundo os autores, os materiais e técnicas utilizadas atualmente não são precisos dimensionalmente, havendo necessidade de futuros desenvolvimentos e estudos.

Em 2001, DUYCK et al. ${ }^{14}$ analisaram in vivo a pré-carga estabelecida após o apertamento dos parafusos em próteses sobre múltiplos implantes através de extensômetros. No mesmo trabalho, também avaliaram in vitro a influência da seqüência de apertamento dos parafusos. A influência da seqüência do torque nos parafusos foi realizada através de um modelo com 6 implantes, sobre o qual foram confeccionadas 4 infra-estruturas. As infraestruturas foram testadas 5 vezes nos intermediários, sendo empregadas as seguintes seqüências de apertamento: 1-2-3-4-5-6; 6-5-4-3-2-1; 6-4-2-5-3-1-; 1 3-5-2-4-6; 5-4-3-6-1-2, com torque de 10Ncm. A análise in vivo contou com 13 pacientes portadores de próteses fixas do tipo protocolo (9 na mandíbula e 4 na maxila), suportadas por 6 implantes, sendo somente uma com 5 implantes. As próteses testadas estavam instaladas nos pacientes com um tempo médio de 4,9 anos e consideradas adequadas. Realizaram 2 testes em cada paciente. Primeiramente, somente o cilindro de ouro foi apertado separadamente em cada intermediário com troque de $10 \mathrm{Ncm}$ a fim de representar uma adaptação passiva. Depois, a pré-carga foi registrada com o apertamento dos parafusos da prótese nos intermediários. Os resultados relativos à seqüência de apertamento dos parafusos não influenciaram o estabelecimento da pré-carga. Entretanto, houve uma grande variação de transmissão de forças de uma mesma prótese nos diferentes intermediários. A justificativa para esses resultados está no fato de que a prótese não estabelece um contato semelhante com todos intermediários. Quando a prótese é apertada, a précarga interna é induzida primeiro nos intermediários mais adaptados e que mantêm um contato mais próximo, transmitindo, portanto, maiores valores de estresse nesses intermediários. A pré-carga interna nos demais só é 
estabelecida quando os espaços de desadaptação entre a prótese e os intermediários são eliminados ou reduzidos. Conseqüentemente, altos valores de pré-carga são gerados em alguns intermediários, enquanto quase nenhuma pré-carga é observada em outros quando a prótese é instalada. Ocorre também uma distorção na prótese durante o apertamento dos parafusos. Quando há desadaptações, podem ser geradas forças de tensão adicionais nos intermediários, impedindo o estabelecimento de uma adequada pré-carga. Concluíram que a seqüência do apertamento dos parafusos não é um fator determinante na pré-carga no caso de próteses clinicamente passivas. A desadaptação de próteses fixas totais sobre vários implantes altera 0 estabelecimento da pré-carga, geralmente reduzindo a transmissão de forças axiais e aumentando a pré-carga externa, o que resulta em uma carga constante nos implantes. Entretanto, ressaltaram que a pré-carga externa resultante de desadaptações nas próteses avaliadas não causou problemas clínicos relevantes no período de avaliação dos pacientes.

Em 2001, através de revisão da literatura sobre a aplicação da análise de elemento finito em Implantodontia, GENG; TAN; LIU ${ }^{16}$ discutiram sobre os achados encontrados com essa metodologia quanto à interface ossoimplante, a conexão prótese-implante e próteses implanto-suportadas por vários implantes. Relataram que as propriedades dos materiais simulados influenciam a distribuição e a manutenção dos esforços no modelo de elemento finito e, por isso, resultados de muitos estudos não podem ser generalizados para situações clínicas. O osso, por exemplo, é um material isotrópico. Significa que tem diferentes propriedades quando medido em diferentes direções e a maioria dos estudos avaliados considera os materiais homogêneos e com propriedades lineares. Ligas metálicas com baixo módulo de elasticidade promovem esforços mais intensos na interface osso-implante e recomendaram a utilização de ligas metálicas rígidas para uma melhor distribuição dos esforços. A distribuição dos esforços em próteses suportadas por vários implantes é de grande complexidade, incluindo os seguintes fatores mecânicos: inclinação e posição dos implantes, forma e extensão da infra-estrutura, material da prótese, comprimento do cantilever, interface entre componentes protéticos e implantes e interface osso-implante. 
Por meio de uma revisão da literatura, TAYLOR; $\mathrm{AGAR}^{54}$, em 2002, inferiram que muitos princípios e parâmetros considerados foco de atenção das próteses implanto-suportadas há vinte anos atrás, foram alterados ao passo que novas idéias e conceitos foram sendo gradativamente estabelecidos. Antes da conferência de Toronto, em 1982, o tratamento com implantes não era aceito como uma alternativa em relação aos procedimentos protéticos tradicionais. Afirmaram que conceitos e princípios empíricos considerados no tratamento de dentes naturais foram extrapolados para as próteses implanto-suportadas. Consideraram importante a redução no custo do tratamento com implantes a fim de se permitir que a população em geral tenha acesso a essa modalidade restauradora.

AKÇA E COLS ${ }^{2}$, em 2002, comparando a análise do estresse por elemento finito tri-dimensional com leituras de extensômetros lineares elétricos em vitro, nas mesmas situações, obtiveram um aumento estatisticamente significante $(P<0,05)$ nos valores de tensão quando a avaliação foi realizada com extensômetros lineares elétricos nos diversos tipos de forças. Concluíram que há diferenças relativas à quantificação das tensões entre os dois sistemas, porém há um consenso mútuo na determinação do tipo de tensão (tração e compressão) induzida pela aplicação das forças.

SHAIN $^{42}$, em 2002, em um artigo de revisão de literatura sobre a influência das forças funcionais sobre os implantes osseointegrados, discorre que a sobrecarga mecânica pode acarretar em falhas biológicas, afirmando que quando uma sobrecarga é aplicada em um implante osseointegrado o osso circunjacente a este implante sofre uma deformação (de 2000 a 3000 "microstrain"). Quando uma sobrecarga patológica ocorre (acima de 4000 "microstrain") o estresse e a tensão gerados excedem o limiar fisiológico tolerado pelo osso e ocorrem microfraturas na interface implante-osso. A aplicação de repetidas cargas podem levar a falha por fadiga da interface, diminuindo a densidade óssea periimplantar e levar a formação de defeitos ósseos tipo crateras. Segundo este autor as falhas tardias em implantes, após a instalação das próteses, são observadas e estão correlacionadas com complicações biomecânicas e que os mecanismos relacionados com estas 
falhas ainda não são totalmente entendidos e a literatura a respeito das influências dos vários fatores biomecânicos é inconclusiva ${ }^{42}$.

GOODACRE $^{19}$ e colaboradores, em 2003, levantaram artigos de 1981 a 2001 os quais relatavam complicações com implantes osseointegráveis e prótese sobre implante. Pelo levantamento realizado, 14 complicações mecânicas foram identificadas na literatura, com uma incidência de 30\% para perda de retenção de overdentures a $1 \%$ para fratura de implantes, onde $7 \%$ relataram afrouxamento do parafuso protético, $6 \%$ Afrouxamento do parafuso do intermediário, $4 \%$ fratura do parafuso protético, 3\% fratura da infra-estrutura e $2 \%$ fratura do parafuso do intermediário.

HECKER e ECKER ${ }^{21}$, em 2003, em um estudo laboratorial onde avaliaram a mudança da adaptação de próteses implanto-suportadas frente a aplicação de forças cíclicas(200Ncm com 50.000 e 200.000 cíclos), onde simularam a situação de uma prótese fixa mandibular com cinco implantes e cantilever distal de $18 \mathrm{~mm}$, avaliando a adaptação das próteses antes e após a aplicação de cargas cíclicas na região anterior e também no cantilever de $18 \mathrm{~mm}$. Os resultados das medidas de desadaptação da prótese aos intermediários demonstraram significante diminuição da interface de desadaptação quando as forças foram aplicadas na região anterior da infraestrutura, já quando as forças foram aplicadas no cantilever distal, uni ou bilateralmente, não foi observada diminuição significante na desadaptação dos componentes da prótese. Concluindo que as aplicações de forças cíclicas em infra-estruturas de prótese sobre implante causam mudanças na adaptação entre a prótese e o intermediário.

STEGAROIU ${ }^{49}$ e cols, em 2004, avaliaram a distribuição de estresse no osso circunjacente, com a utilização de extensômetros lineares elétricos, ao implante restaurado com coroas metálicas recobertas com de três diferentes materiais: compômero, resina acrílica e liga de ouro, com a aplicação de força lateral estática e dinâmica sem impacto de $100 \mathrm{Ncm}$. O estudo demonstrou que os diversos materiais de cobertura das próteses tiveram a mesma influência no estresse transmitido ao osso circunjacente a uma prótese implanto suportada unitária. 
WEINER $^{59}$ e colaboradores, em 2004, avaliaram a resposta sensorial do nervo alveolar inferior frente a aplicação de forças em implantes osseointegrados na mandíbula de cães. Relataram que: a aplicação de forças vibratórias nos implantes resultou na geração de potencial de ação no nervo alveolar inferior, o limiar para geração de potenciais de ação é maior nos implantes do que o dos dentes naturais adjacentes e que a latência da resposta é similar tanto no dente como no implante. 


\section{ProposiçÃo}




\section{3 - PROPOSIÇÃO}

A proposta deste trabalho "in vitro" é analisar, frente a aplicação de uma carga estática de $100 \mathrm{~N}$ em um cantilever de $15 \mathrm{~mm}$, com a utilização de extensômetros lineares elétricos:

1. A deformação gerada nos componentes intermediários de prótese fixa implanto-suportada com diferentes alturas.

2. A deformação nos intermediários utilizando-se de infra-estruturas de cobalto-cromo e paládio-prata. 
MATERIAL E MÉTOdOS 


\section{4 - MATERIAL E MÉTODOS}

\subsection{OBTENÇÃO DA AMOSTRA:}

Para obtenção dos corpos de provas necessários para a realização dos testes, foram utilizados:

- 5 análogos do implante master screw 3,75mm (código 13 - CNB Conexão Sistemas de Prótese Ltda - São Paulo, Brasil);

- 05 intermediários convencionais ("standard") com anti-rotacional em 2 peças, de $4 \mathrm{~mm}$ de altura por 3,75 $\mathrm{mm}$ de diâmetro (código 09 CNB - B - Conexão Sistemas de Prótese Ltda - São Paulo, Brasil);

- 05 intermediários convencionais ("standard") com anti-rotacional em 2 peças, de 5,5mm de altura por 3,75 $\mathrm{mm}$ de diâmetro (código 09 CNB - B - Conexão Sistemas de Prótese Ltda - São Paulo, Brasil);

- 05 intermediários convencionais ("standard") com anti-rotacional em 2 peças, de $7 \mathrm{~mm}$ de altura por 3,75 $\mathrm{mm}$ de diâmetro (código 09 CNB - B - Conexão Sistemas de Prótese Ltda - São Paulo, Brasil);

- 15 parafusos de titânio com hexágono (código 108 - CNB, - Conexão Sistemas de Prótese Ltda - São Paulo, Brasil);

- 05 copings de plástico para abutment "standard" (código 96 - CNB, Conexão Sistemas de Prótese Ltda - São Paulo, Brasil);

- 05 copings de Pors-on para abutment "standard" (código 95 - CNB, Conexão Sistemas de Prótese Ltda - São Paulo, Brasil);

- 02 infra-estruturas para prótese fixa implanto suportada, uma em PdAg e outra em CoCr;

- 01 modelo mestre simulando uma mandíbula com 5 implantes. 


\subsection{OBTENÇÃO DO MODELO MESTRE:}

Foi confeccionado, em aço comum (Aço 1010/20), um modelo mestre de forma circular, com $67 \mathrm{~mm}$ de diâmetro interno, $79 \mathrm{~mm}$ de diâmetro externo e $25 \mathrm{~mm}$ de altura. Cinco perfurações paralelas a uma distância de $7 \mathrm{~mm}$, de centro a centro, com $3,75 \mathrm{~mm}$ de diâmetro, foram realizadas na porção superior do modelo mestre, de modo que as réplicas de fixação pudessem ser adaptadas com precisão, de modo que sua porção superior ficasse no nível da superfície do modelo mestre (Figura 4.1). Para evitar qualquer tipo de deslocamento, cada réplica foi fixada por meio de um parafuso tipo "Allen", sem cabeça (modelo M3 $\times 10 \mathrm{~mm}$ ), transfixando o modelo mestre no sentido horizontal ${ }^{25,32,35}$.

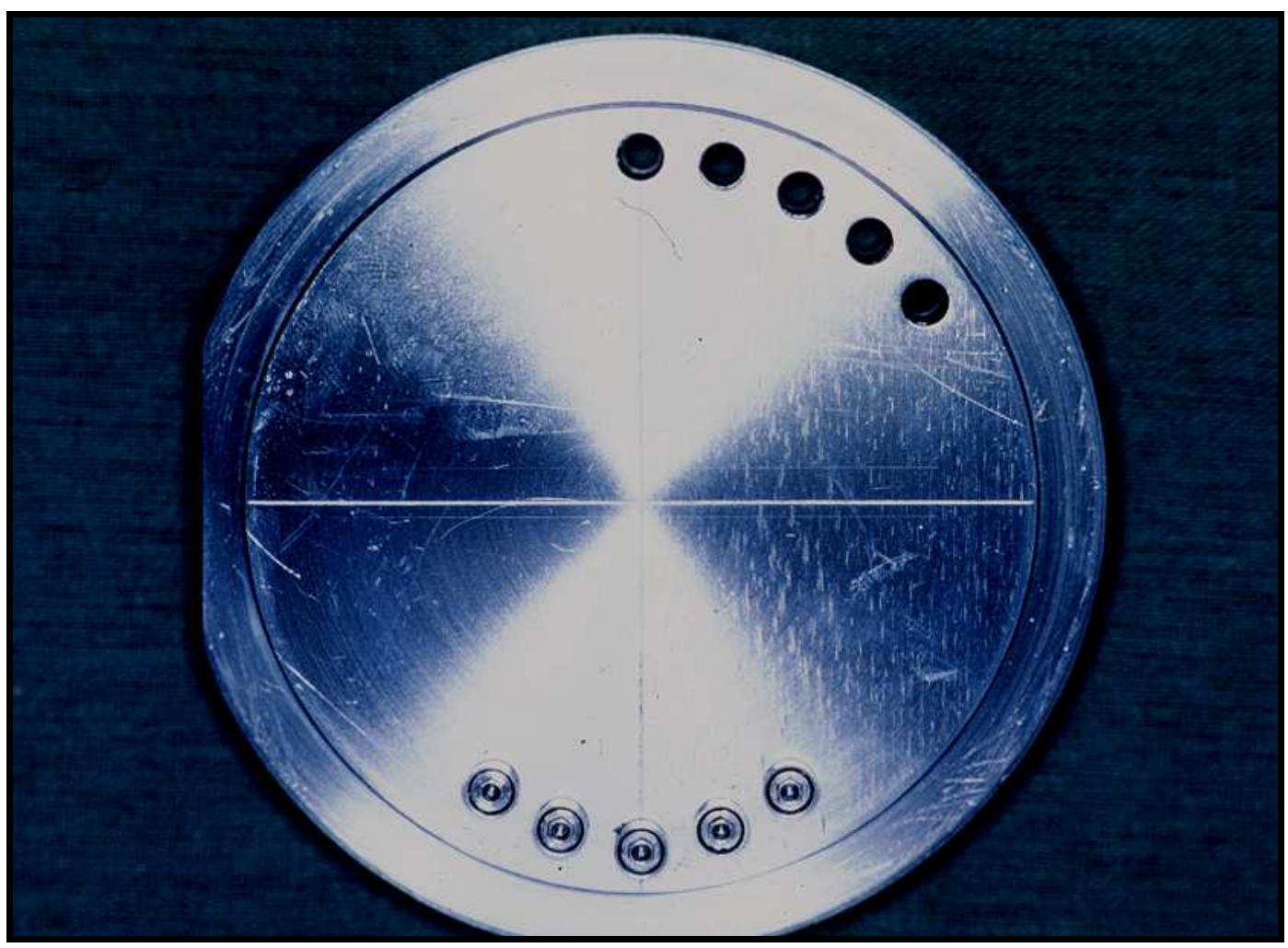

Figura 4.1. Vista superior do modelo mestre com os análogos posicionados. 


\subsection{OBTENÇÃO DAS INFRA-ESTRUTURAS}

Foram confeccionadas duas barras com ligas metálicas diferentes com dimensões de $75 \mathrm{~mm}$ de comprimento, $6 \mathrm{~mm}$ de largura e $4 \mathrm{~mm}$ de expessura, sendo que a extensão da extremidade livre corresponde a $23,5 \mathrm{~mm}$, em ambos os lados. Na porção superior das extremidades livres foram preparadas pequenas depressões, a uma distância de 10, 15 e 20mm do centro da réplica de fixação terminal, para permitir a acomodação da ponta aplicadora da carga ${ }^{25}$.

\subsubsection{INFRA-ESTRUTURA DE COBALTO-CROMO:}

Para confecção da infra-estrutura na liga de cobalto-cromo (Rexillium ${ }^{\circledR}$ N.B.F. - Jeneric ${ }^{\circledR} /$ Pentron $^{\circledR}$ Incorporated), cilindros de plástico foram fundidos individualmente (Figura 4.2) e posteriormente posicionados nos análogos de implantes e parafusados, utilizando-se parafusos de titânio com hexágono. Com os intermediários em posição a infra-estrutura foi encerada diretamente no modelo mestre (figura 4.3). Uma matriz de silicone foi feita a partir desta barra conseguindo assim a padronização das dimensões da infra-estrutura, para posterior enceramento da barra de PdAg. A seguir, procedeu-se a fundição da barra de $\mathrm{CoCr}$ (figura 4.4) 


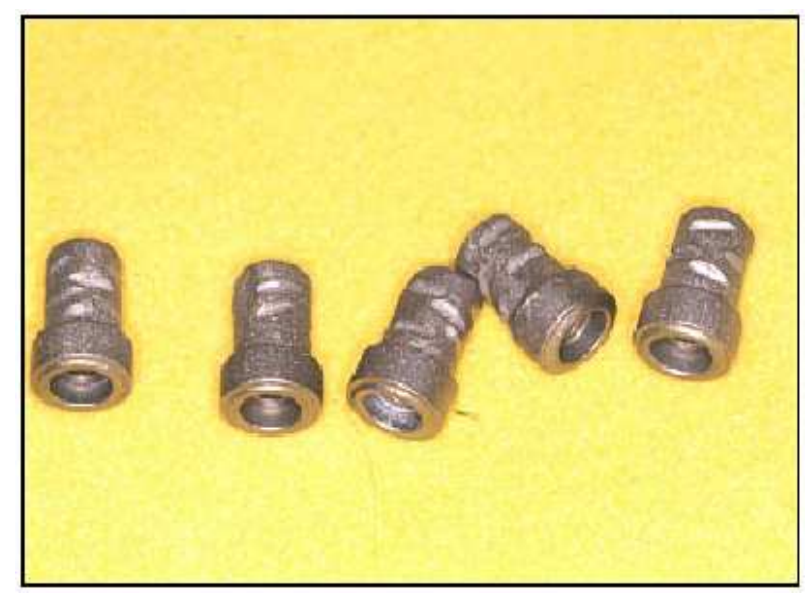

Figura 4.2. Vista dos cilindros fundidos em CoCr.

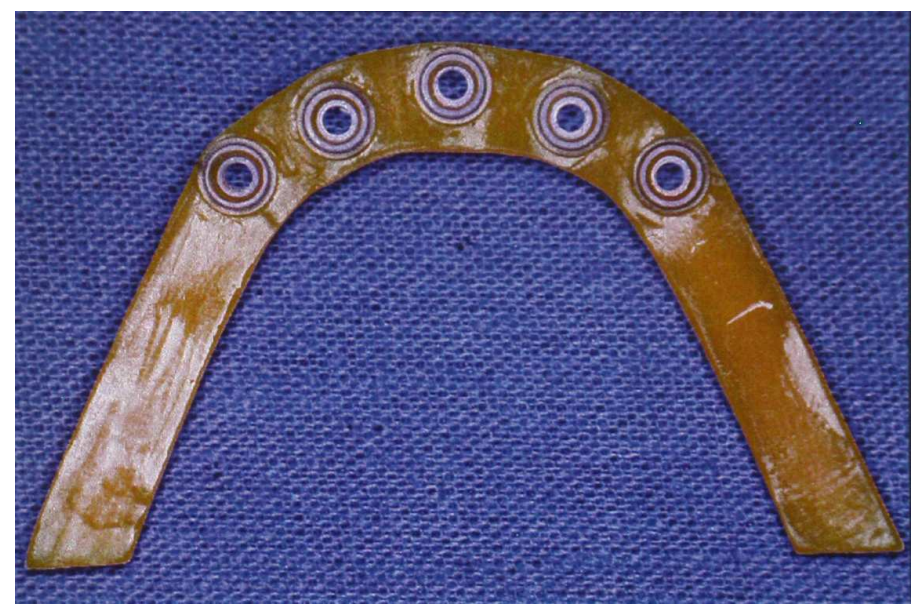

Figura 4.3. Vista inferior da infra-estrutura de encerada. 


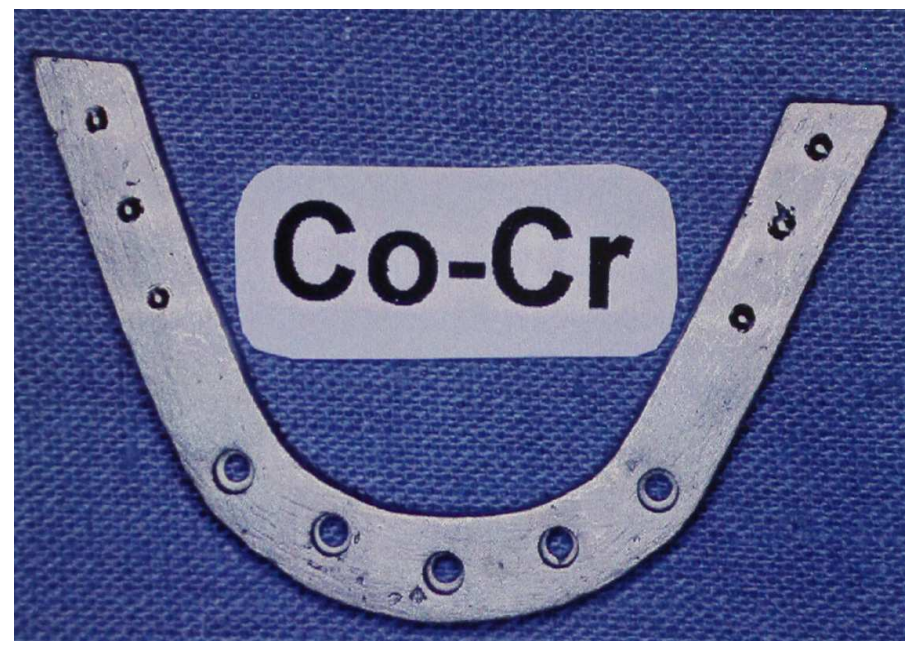

Figura 4.4. Vista superior da infra-estrutura de CoCr.

\subsubsection{INFRA-ESTRUTURA DE PALÁDIO-PRATA:}

Para a infra-estrutura na liga de paládio-prata (Pors-on ${ }^{\circledR} 4$ Degussa S.A., São Paulo, Brasil) os cilindros de Pors-on® foram posicionados e parafusados nos intermediários, utilizando os parafusos de titânio com hexágono. A matriz de silicone foi posicionada sobre o modelo mestre e cera para incrustação aquecida e liquefeita foi despejada através de uma abertura superior. O conjunto foi mantido em repouso até o completo resfriamento e endurecimento da cera. A matriz de silicone foi removida e pequenos acabamentos foram realizados (figura 4.5). Com isso foi possível manter as mesmas dimensões para a barra de Pd-Ag (figura 4.6). 


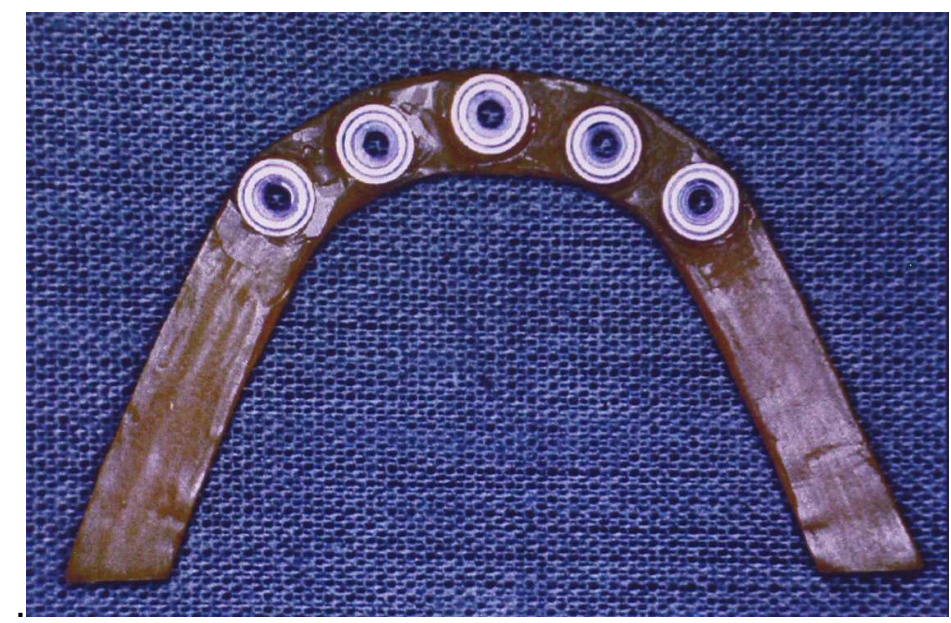

Figura 4.5. Vista inferior da infra-estrutura encerada sobre os componentes de PdAg.

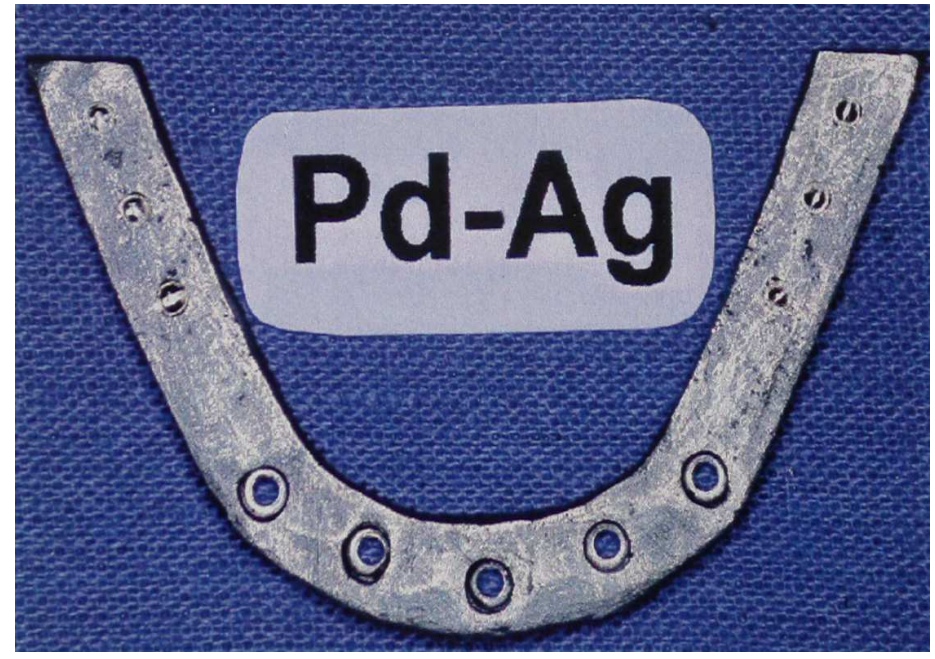

Figura 4.6. Vista superior da infra-estrutura de PdAg. 
Tabela 1: ESPECIFICAÇÕES DAS LIGAS UTILIZADAS, SEGUNDO OS FABRICANTES:

\begin{tabular}{|c|c|c|c|c|c|}
\hline LIGA & LOTE № & CONTEÚDO & $\begin{array}{l}\text { INTERVALO } \\
\text { DE FUSÃO } \\
\text { (으) }\end{array}$ & $\begin{array}{l}\text { MÓDULO DE } \\
\text { ELASTICIDADE } \\
\text { (GPa) }\end{array}$ & $\begin{array}{c}\text { PESO } \\
\text { ESPECÍFICO } \\
\left(\mathbf{g} / \mathrm{cm}^{3}\right)\end{array}$ \\
\hline $\begin{array}{c}\text { Rexillium }^{\circledR} \\
\text { N.B.F. } \\
\text { (Jeneric }{ }^{\circledR} / \\
\text { Pentron }^{\circledR} \text { ) }\end{array}$ & 092297-84 & $\begin{array}{l}\mathrm{Co}-52 \% \\
\mathrm{Cr}-25 \% \\
\mathrm{~W}-14 \% \\
\mathrm{Ga}-8 \%\end{array}$ & $1232-1315$ & 219,80 & 7,85 \\
\hline $\begin{array}{c}\text { Pors-on } 4^{\circledR} \\
\text { (Degussa }^{\circledR} \\
\text { S.A.) }\end{array}$ & 90171 & $\begin{array}{c}\mathrm{Pd}-57,8 \% \\
\mathrm{Ag}-30 \%\end{array}$ & $1175-1275$ & $95^{12}$ & 11,40 \\
\hline
\end{tabular}




\subsection{OBTENÇÃO DOS GRUPOS:}

Os grupos foram divididos de acordo com o tipo de liga da barra, quais sejam:

GRUPO 1 - CoCr_Rexillium ${ }^{\circledR}$ N.B.F. - Jeneric ${ }^{\circledR} /$ Pentron $^{\circledR}$ Incorporated:

CP 1 - Infra-estrutura em liga de cobalto-cromo fixada sobre intermediários protéticos com altura de 4,0mm.

CP 2 - Infra-estrutura em liga de cobalto-cromo fixada sobre intermediários protéticos com altura de $5,5 \mathrm{~mm}$.

CP 3 - Infra-estrutura em liga de cobalto-cromo fixada sobre intermediários protéticos com altura de 7,0mm.

GRUPO 2 - PdAg_Pors-on ${ }^{\circledR} 4$ - Degussa S.A., São Paulo, Brasil:

CP 4 - Infra-estrutura em liga de paládio-prata fixada sobre intermediários protéticos com altura de 4,0mm.

CP 5 - Infra-estrutura em liga de paládio-prata fixada sobre intermediários protéticos com altura de $5,5 \mathrm{~mm}$.

CP 6 - Infra-estrutura em liga de paládio-prata fixada sobre intermediários protéticos com altura de 7,0mm. 


\subsection{COLAGEM E CONEXÃO DOS EXTENSÔMETROS:}

Em uma primeira etapa, os intermediários foram posicionados sobre as réplicas, no modelo mestre, para realização de demarcações na região mesial e distal de cada intermediário, os quais foram numerados de 1 a 5 , a começar pelo lado que posteriormente recebeu a aplicação da força .

Em seguida, dois extensômetros lineares elétricos (KFG -02-120C1-11, Strain Gages - Kyowa Electronic Instruments Co., Ltd., Tóquio, Japão) foram fixados com uma cola a base de cianoacrilato (Strain Gage Cement CC 33 A -Kyowa Electronic Instruments Co., Ltd., Tóquio, Japão), no centro das faces externas mesial e distal de cada intermediário. Posteriormente, os intermediários foram posicionados e parafusados com um torque de $20 \mathrm{Ncm}$, através de um dispositivo eletrônico de controle de torque (Nobel Biocare Torque Controller TM, Gotemburgo, Suécia).

As terminações dos extensômetros lineares elétricos foram soldadas em uma placa de circuito elétrico que foi afixada sobre a superfície do modelo mestre. Cada um dos extensômetros lineares elétricos foi conectado a um canal de uma placa de aquisição de dados (SC - 2042 - SG, National Instruments Corp, Austin, Texas, USA. Figura 4.7), a qual tem a função de receber os sinais elétricos da tensão gerada nos intermediários pela aplicação da força na extremidade livre da infra-estrutura, transformá-los em sinais digitais e enviá-los para uma placa de leitura (PCI - MIO - 16 XE - 10, National Instruments Corp. Austin, Texas, USA), instalada em um microcomputador Pentium II $133 \mathrm{MHz}, 16 \mathrm{Mb}$. Através deste, os dados obtidos puderam ser visualizados, com a utilização do programa LabVIEW FDS(CD-ROM), versão 5.1 para Windows (National Instruments Corp. Austin, Texas, USA) ${ }^{25,32,35 .}$ 


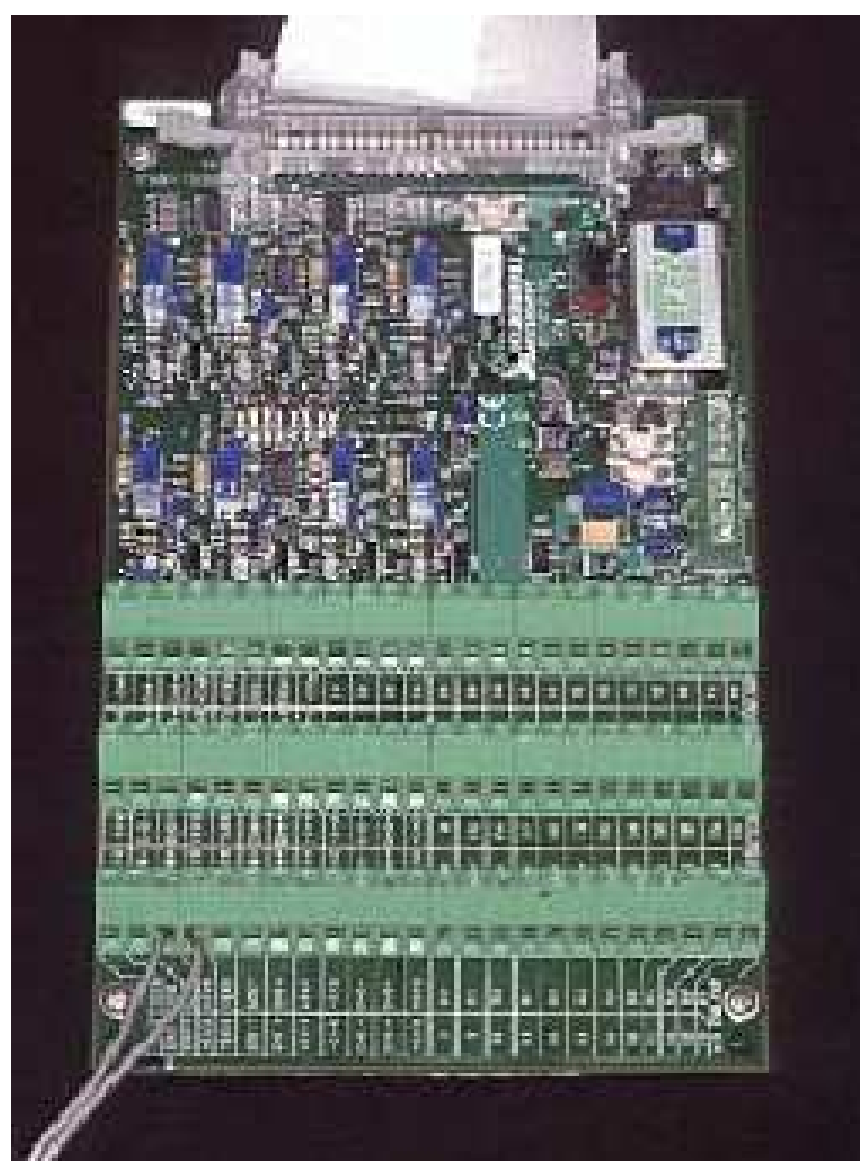

Figura 4.7. Vista superior da placa de aquisição de dados conectada a um canal de extensometria.

\subsection{FIXAÇÃO DA INFRA-ESTRUTURA:}

A infra-estrutura foi posicionada sobre os intermediários no modelo mestre. Numa primeira fase, os parafusos de titânio receberam um aperto manual, com a utilização de uma chave hexagonal, até oferecerem resistência. Posteriormente, um torque de $10 \mathrm{Ncm}$ foi empregado em cada parafuso por meio de um dispositivo eletrônico de controle de torque (Nobel Biocare Torque Controller T⿳, Gotemburgo, Suécia) de acordo com a seqüência ideal de aperto dos parafusos de titânio proposta por $\mathrm{JEMT}^{27}$, na seguinte 
ordem: $2,4,3,1,5$ consederando-se o intermediário terminal direito o ํo $1 \mathrm{e}$ seguindo-se no sentido contrário a aplicação da carga até o de ㄲo 5 (figura 4.8).

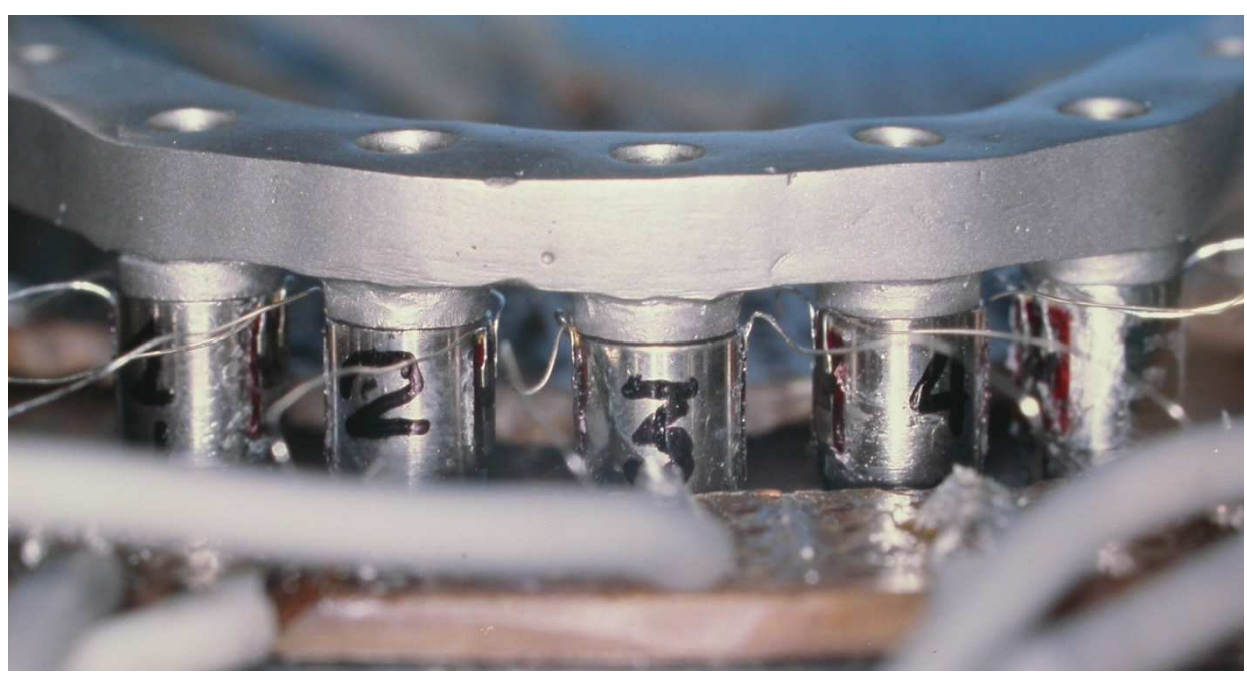

Figura 4.8. Infra-estrutura fixada sobre os intermediários com extensômetros lineares elétricos colados nas faces proximais.

\subsection{REALIZAÇÃO DO TESTE}

O modelo mestre foi adaptado à Máquina Universal de Ensaio Kratos ( modelo K - 2000 MP - Kratos Equipamentos Industriais Ltda., Taboão da Serra, São Paulo, Brasil), através de um dispositivo que permite a sua movimentação em todas as direções no plano horizontal, permitindo o correto posicionamento da ponta aplicadora de carga ${ }^{25}$.

Uma ponta em aço comum, na forma de lápis, foi fixada à célula de carga e uma força de $100 \mathrm{~N}$ foi aplicada, a uma velocidade de $0,5 \mathrm{~mm} / \mathrm{min}$, em um ponto de referência pré-determinado na extremidade livre, a uma distância de $15 \mathrm{~mm}$ do centro da réplica de fixação terminal, em apenas um lado da barra. Foram realizadas cinco aplicações de força para cada corpo de 
prova, durante as quais, foram realizadas as leituras da deformação, na mesial e na distal de cada intermediário (figura 4.9).

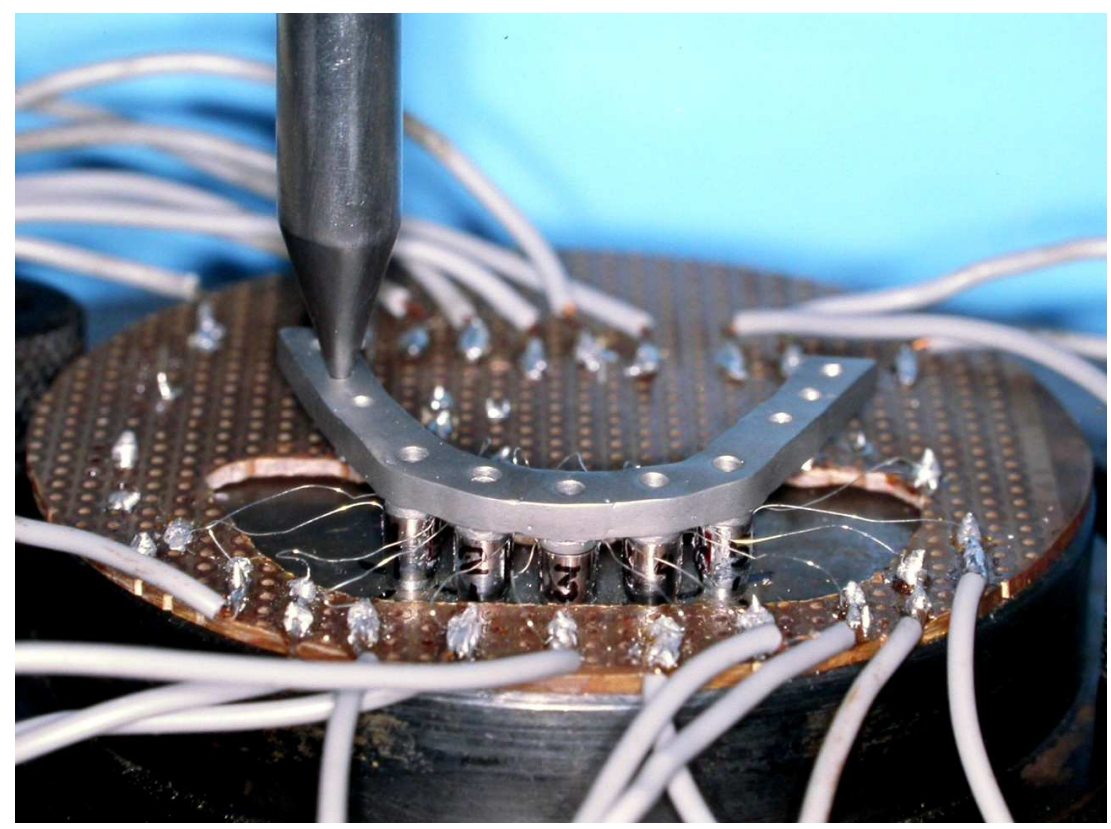

Figura 4.9. Aplicação da força estática de $100 \mathrm{~N}$ a $15 \mathrm{~mm}$ de distância do centro do intermediário 1.

As leituras da microdeformação dos intermediários de cada corpo de prova foram realizadas com a utilização dos extensômetros lineares elétricos em todos os intermediários. Ao todo, foram empregados 10 extensômetros lineares elétricos para cada teste, os quais foram conectados a 10 canais correspondentes, na placa de aquisição de dados, a partir do intermediário 1 (figura 4.10):

- Canal $0(\mathrm{CO})$ - superfície distal do intermediário 1;

- $\quad$ Canal $1(\mathrm{C} 1)$ - superfície mesial do intermediário 1;

- $\quad$ Canal 2 (C2) - superfície distal do intermediário 2;

- $\quad$ Canal 3 (C3) - superfície mesial do intermediário 2;

- $\quad$ Canal 4 (C4) - superfície do intermediário 3 voltada para o 2;

- $\quad$ Canal 5 (C5) - superfície do intermediário 3 voltada para o 4; 
- $\quad$ Canal 6 (C6) - superfície mesial do intermediário 4;

- $\quad$ Canal 7 (C7) - superfície distal do intermediário 4;

- Canal 0' (C0’) - superfície mesial do intermediário 5;

- $\quad$ Canal 1' (C1') - superfície distal do intermediário 5.

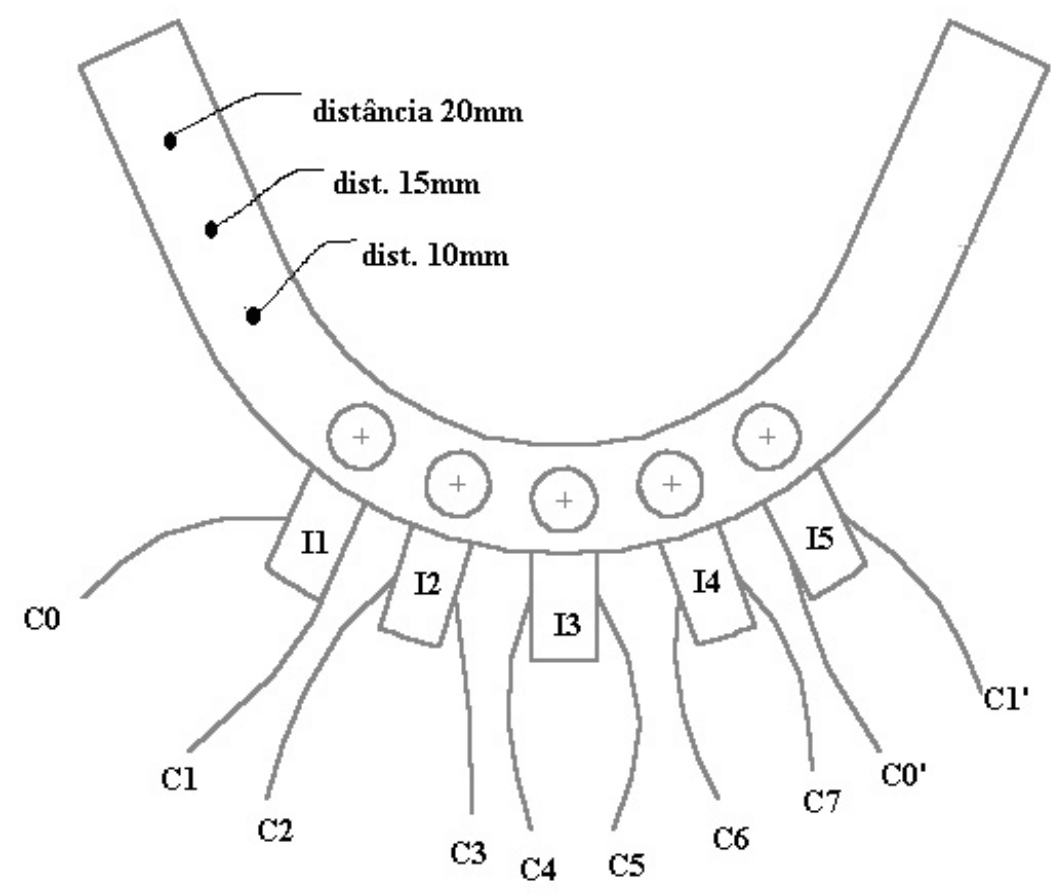

Figura 4.10. Desenho esquemático da disposição dos canais de aquisição (C) e dos intermediários (I).

Devido ao fato de que a placa de aquisição de dados possui entrada para apenas 8 canais, os canais do intermediário 5 foram numerados de 0 ' e 1'. Sendo feita a captação da deformação destes dois últimos extensômetros num segundo momento, havendo a necessidade de desconectar os canais 6 e 7 da placa para possibilitar a leitura dos canais 0'e 1 '. 
Através do programa LabVIEW FDS(CD-ROM), os dados foram visualizados no monitor do computador e armazenados obtendo-se 1 dado numérico de microdeformação a cada $1 / 4$ de segundo durante todo o tempo necessário para ocorrer a estabilização da deformação em todos os canais.

\subsection{AQUISIÇÃO DOS DADOS:}

O extensômetro linear elétrico ou "strain gauge" é um dispositivo elétrico capaz de medir a tensão sofrida por um objeto. A tensão $(\varepsilon)$ representa a quantidade de deformação de um corpo quando submetido a uma determinada força, que pode ser de tração $(+)$ ou de compressão $(-)^{4}$.

Quando um material é tensionado ele sofre um alongamento, determinado deformação absoluta $(\Delta \mathrm{L})$, que é proporcional à força nele aplicada. A proporção entre a variação do comprimento $(\Delta \mathrm{L})$ de um corpo e seu tamanho inicial $(\mathrm{L})$ corresponde à deformação específica $(\varepsilon)$, expressa pela fórmula:

$$
\varepsilon=\frac{\Delta \mathrm{L}}{\mathrm{L}} \frac{(\mathrm{mm})}{(\mathrm{mm})}
$$

Como as unidades de medida de $\Delta \mathrm{L}$ e $\mathrm{L}$ são as mesmas, pode-se entender que a deformação específica é uma medida adimensional, isto é, não representa uma unidade. Indica apenas que o número por ele representado refere-se a um valor de deformação específica, ou a uma porcentagem de deformação.

A medida de deformação fornecida pelos extensômetros é representada por "micro strain" $(\mu \varepsilon)$, em que o micro $(\mu)$ corresponde à potência de $1 \times 10^{-6}$ ou 0,000001 . 
Os extensômetros constituem-se resistências elétricas nas quais percorre uma corrente elétrica de baixa intensidade através de um circuito elétrico de ponte de Wheatstone ${ }^{4}$.

Quando sofre qualquer deformação, a resistência elétrica do extensômetro é alterada, gerando uma tensão de saída nos terminais da ponte. Esses sinais elétricos são enviados pelos canais para a placa de aquisição de dados.

Esta, por sua vez, transforma os sinais elétricos em sinais digitais, enviando-os para a placa de leitura instalada no computador. Através do programa LabVIEW FDS(CD-ROM), os dados são transformados em valores de deformação específica, permitindo a visualização das deformações em tempo real.

Após o aperto dos intermediários com torque de $20 \mathrm{Ncm}$, os extensômetros realizaram a medida dos valores respectivos à tensão sofrida pelo apertamento dos parafusos. Para que essa deformação não interferisse nos resultados, essa leitura foi zerada antes da realização de nova medida durante a aplicação da carga de $100 \mathrm{Ncm}$ a $15 \mathrm{~mm}$ da região distal do intermediário $\mathrm{n}^{0} \mathbf{1}$.

Todos os dados foram gravados no computador como arquivos de extensão DAT. Em seguida, transferidos como arquivos de extensão XLS para o programa EXCEL, a fim de que fosse realizada a análise e seleção dos dados.

Os valores de deformação medidos por cada um dos extensômetros lineares elétricos passam por 3 fases distintas:

- Na fase inicial ocorrem variação de baixa magnitude, que correspondem ao período compreendido entre o momento em que se liga a aparelhagem e a estabilização das leituras; estas variações são da ordem de +16,648 a $-16,648 \mu \varepsilon$ e correspondem ao limite de sensibilidade dos extensômetros lineares elétricos. 
- $\quad \mathrm{Na}$ fase intermediária observam-se as leituras compreendidas entre o momento em que a ponta da máquina de ensaios toca a barra até o momento em que a força atinge $100 \mathrm{~N}$; a deformação é crescente em função do tempo.

- Na fase final, os valores de deformação se estabilizam e permanecem num patamar de deformação máxima para a carga aplicada (Figura 4.11).

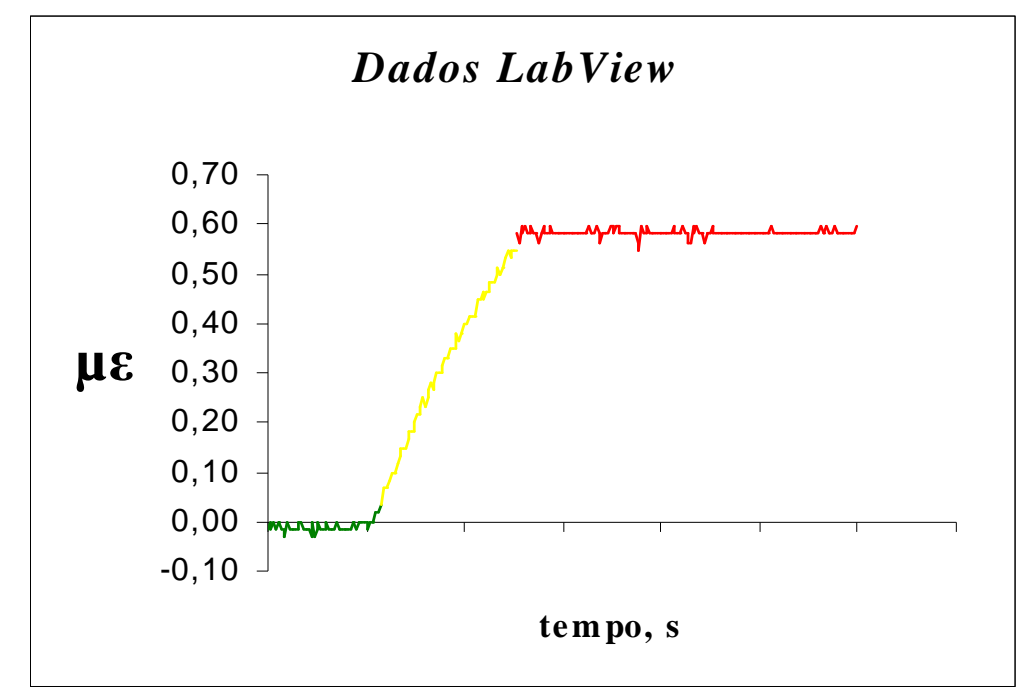

\begin{tabular}{|c|l|}
\hline----- & Dados Iniciais \\
\hline--- & Dados Intermediários de Variação da Carga \\
\hline----- & Dados Finais \\
\hline
\end{tabular}

Figura 4.11. Fases das variações dos valores de deformação.

Foram realizadas 5 repetições de aplicação de carga para cada corpo de prova. Para efeito de cálculo da deformação média, foram considerados somente os 100 últimos valores de deformação captados pelos extensômetros lineares elétricos, por corresponderem aos valores máximos e estáveis de deformação. O valor médio de deformação em cada canal é, portanto, resultado de 500 leituras realizadas. 
Resultados E Discussão 


\section{5 - RESULTADOS E DISCUSSÃO}

Os valores numéricos obtidos são expressos como tração (valores positivos) e compressão (valores negativos).

A média dos cinco resultados obtidos com a realização dos experimentos, em cada corpo de prova do grupo I, com infra-estrutura confeccionada com a liga de CoCr, estão nas tabelas abaixo.

Tabela 2 - Médias dos resultados de microdeformação no corpo de prova I (intermediários de $4,0 \mathrm{~mm}$ de altura).

\begin{tabular}{|c|c|c|}
\hline Intermediário & Canal & Microdeformação $(\mu \varepsilon)$ \\
\hline \multirow{2}{*}{11} & $\mathrm{CO}$ & 7,490 \\
\hline & C1 & $-48,310$ \\
\hline \multirow{2}{*}{12} & $\mathrm{C} 2$ & 36,660 \\
\hline & C3 & 216,000 \\
\hline \multirow{2}{*}{13} & C4 & 146,62 \\
\hline & C5 & 38,125 \\
\hline \multirow{2}{*}{14} & C6 & 105,990 \\
\hline & C7 & $-15,648$ \\
\hline \multirow{2}{*}{15} & CO' & $-1,332$ \\
\hline & C1' & $-66,320$ \\
\hline
\end{tabular}


Tabela 3 - Médias dos resultados de microdeformação no corpo de prova II (intermediários de 5,5 $\mathrm{mm}$ de altura).

\begin{tabular}{l|l|r}
\hline \multirow{2}{*}{ Intermediário } & Canal & Microdeformação $(\mu \varepsilon)$ \\
& C0 & $-496,959$ \\
\cline { 2 - 4 } & C1 & $-41,151$ \\
\hline 12 & C2 & $-66,319$ \\
\cline { 2 - 4 } & C3 & $-31,063$ \\
\hline 13 & C4 & 16,715 \\
\hline & C5 & 21,543 \\
\hline 14 & C6 & 48,347 \\
\cline { 2 - 4 } & C7 & $-45,313$ \\
\hline I5 & C0' & $-58,862$ \\
\cline { 2 - 3 } & C1' & 13,318 \\
\cline { 2 - 3 } & & \\
\hline
\end{tabular}

Tabela 4 - Médias dos resultados de microdeformação no corpo de prova III (intermediários de 7,0 $\mathrm{mm}$ de altura).

\begin{tabular}{l|l|r}
\hline \multirow{2}{*}{ Intermediário } & Canal & Microdeformação $(\mu \varepsilon)$ \\
& C0 & $-514,819$ \\
\cline { 2 - 4 } & C1 & 33,594 \\
\hline \multirow{2}{*}{12} & C2 & 5,327 \\
\cline { 2 - 4 } & C3 & $-3,695$ \\
\hline 13 & C4 & $-2,231$ \\
\cline { 2 - 4 } & C5 & 2,264 \\
\hline 14 & C6 & 6,859 \\
\cline { 2 - 4 } & C7 & $-7,358$ \\
\hline I5 & C0' & 5,161 \\
\cline { 2 - 4 } & C1' & $-3,463$ \\
\hline & & \\
\hline
\end{tabular}


Seguindo a mesma metodologia usada para aplicação dos testes no grupo I, os valores de microdeformação para os corpos de prova do grupo II, com infra-estruturas confeccionadas em liga de PdAg, estão representados nas tabelas que seguem:

Tabela 5 - Médias dos resultados de microdeformação no corpo de prova IV (intermediários de $4,0 \mathrm{~mm}$ de altura).

\begin{tabular}{l|l|r}
\hline \multirow{2}{*}{ Intermediário } & Canal & Microdeformação $(\mu \varepsilon)$ \\
& C0 & 8,490 \\
\cline { 2 - 3 } & C1 & 7,192 \\
\hline 12 & C2 & 127,639 \\
\cline { 2 - 3 } & C3 & 146,423 \\
\hline 13 & C4 & $-2,364$ \\
\cline { 2 - 3 } & C5 & 79,483 \\
\hline 14 & C6 & 79,982 \\
\cline { 2 - 3 } & C7 & $-28,699$ \\
\hline 15 & C0' & 0,833 \\
\cline { 2 - 3 } & C1' & $-29,843$ \\
\hline & &
\end{tabular}


Tabela 6 - Médias dos resultados de microdeformação no corpo de prova V (intermediários de 5,5 $\mathrm{mm}$ de altura).

\begin{tabular}{l|l|r}
\hline \multirow{2}{*}{ Intermediário } & Canal & Microdeformação $(\mu \varepsilon)$ \\
& C0 & $-230,677$ \\
\cline { 2 - 4 } & C1 & $-142,658$ \\
\hline 12 & C2 & $-39,853$ \\
\cline { 2 - 4 } & C3 & 218,436 \\
\hline 13 & C4 & $-1,931$ \\
\cline { 2 - 4 } & C5 & 3,429 \\
\hline 14 & C6 & 5,561 \\
\cline { 2 - 4 } & C7 & $-66,153$ \\
\hline I5 & C0' & $-85,86$ \\
\cline { 2 - 3 } & C1' & 5,864 \\
\cline { 2 - 3 } & & \\
\hline
\end{tabular}

Tabela 7 - Médias dos resultados de microdeformação do corpo de prova VI (intermediários de 7,0 $\mathrm{mm}$ de altura).

\begin{tabular}{l|l|r}
\hline \multirow{2}{*}{ Intermediário } & Canal & Microdeformação $(\mu \varepsilon)$ \\
& C0 & $-322,250$ \\
\cline { 2 - 4 } & C1 & $-30,797$ \\
\hline 12 & C2 & 3,263 \\
\cline { 2 - 4 } & C3 & $-8,789$ \\
\hline \multirow{2}{*}{13} & C4 & $-39,486$ \\
\cline { 2 - 4 } & C5 & 99,131 \\
\hline 14 & C6 & 19,345 \\
\cline { 2 - 4 } & C7 & 4,894 \\
\hline \multirow{2}{*}{15} & C0' & $-95,514$ \\
\cline { 2 - 3 } & C1' & 6,439 \\
& & \\
\hline
\end{tabular}


De acordo com os resultados obtidos podemos observar que o padrão de distribuição das deformações geradas pela aplicação da força estática, a uma distância de $15 \mathrm{~mm}$ do centro do implante terminal (11), variou de acordo com a posição em que os canais de extensometria estavam posicionados nas faces dos intermediários ( $\mathrm{C} 0, \mathrm{C} 1, \mathrm{C} 2, \mathrm{C} 3, \mathrm{C} 4, \mathrm{C} 5, \mathrm{C} 6, \mathrm{C} 7$, C0' e C1'), de acordo com a posição ocupada pelo implante em relação à aplicação da força ( $11,12,13,14$ e 15), devido a variação da altura dos intermediários ( 4,0; 5,5 e 7,0 mm) e também de acordo com o tipo de liga utilizada para confecção das infra-estruturas.

A localização dos extensometros lineares elétricos seguiu como critério o trabalho de RUBO et al. ${ }^{41}$, o qual, por meio de análise de elemento finito, determinou serem as superfícies mesial e distal dos intermediários as áreas mais susceptíveis a tensões diante de uma carga oclusal.

Para a mensuração das deformações sofridas nos intermediários de uma prótese fixa mandibular implanto-suportada, que é a intenção deste estudo, foi necessário a utilização de um componente protético que apresentasse ao mesmo tempo a indicação para a situação clínica simulada e permitisse a colagem dos extensometros lineares elétricos no centro das suas superfícies mesial e distal, independente do formato do intermediário utilizado.

A intenção deste estudo foi a de avaliar o comportamento biomecânico de todo o sistema envolvido em uma prótese fixa mandibular implanto-suportada. Não é o objetivo deste estudo avaliar qual dos intermediários, e nem mesmo afirmar qual dos lados dos intermediários se comportou melhor. Na realidade, todos devem ser considerados em conjunto e não isoladamente.

Também não podemos fazer uma somatória das deformações sofridas em cada lado de cada intermediário e considerar esse valor como deformação do conjunto, pois cada um pode se encontrar sob condições diversas de adaptação e carga. 
Em vista disso, torna-se necessária uma avaliação qualitativa dos resultados, que nos dê uma visão do comportamento biomecânico de todo o sistema e não de intermediários ou extensômetros individualmente.

As figuras 5.1 e 5.2 mostram as ilustrações gráficas dos resultados dos testes realizados com os corpos de prova dos grupos I e II, com infra-estruturas em $\mathrm{CoCr}$ e $\mathrm{PdAg}$, respectivamente. Onde os valores positivos (+) representam forças de deformação por tração, enquanto os valores negativos (-) significam as forças de deformação por compressão. No eixo das abscissas $(y)$, tem-se a deformação, em "microstrains" $(\mu \varepsilon)$, enquanto no eixo das coordenadas $(\mathrm{x})$ estão representados os canais de extensômetros, onde cada dois canais de extensômetros correspondem aos lados mesial e distal dos intermediários:

\author{
Intermediário 1: C0 e C1 \\ Intermediário 2: C2 e C3 \\ Intermediário 3: C4 e C5 \\ Intermediário 4: C6 e C7 \\ Intermediário 5: C0' e C1'
}




\section{Deformação CoCr}

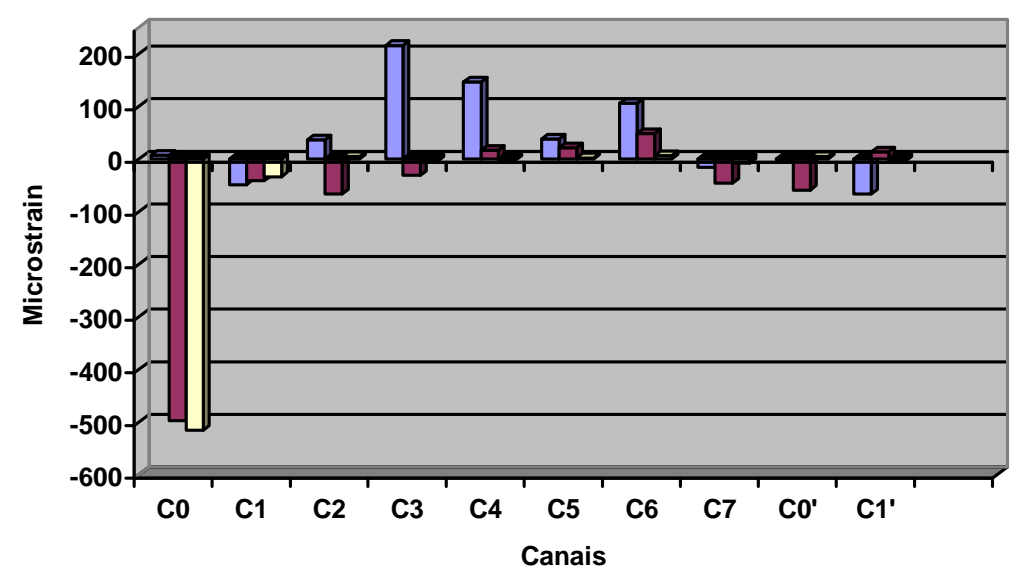

Figura 5.1. Gráfico das médias de microdeformação captadas pelos canais de extensometria dos intermediários dos corpos de prova do grupo I.

\section{Deformação PdAg}

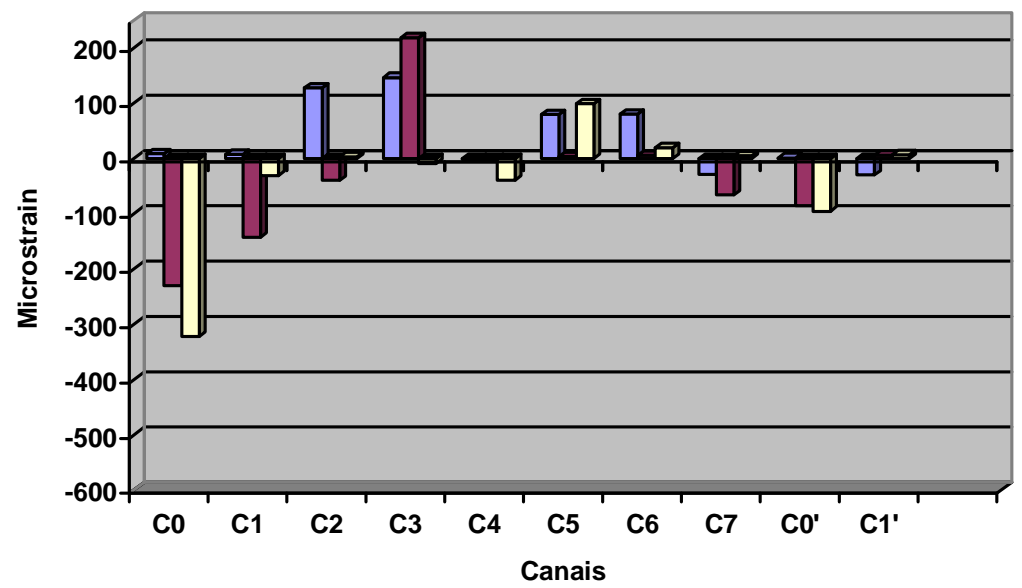

Figura 5.2. Gráfico das médias de microdeformação captadas pelos canais de extensometria dos intermediários dos corpos de prova do grupo II. 
Como podemos observar nos gráficos acima, as tensões geradas nos intermediários não apresentaram um padrão uniforme entre os lados dos intermediários e nem mesmo nos diferentes intermediários. Entretanto, as forças de compressão estão presentes em maior magnitude nos canais situados no intermediário mais próximo à aplicação da força ( $\mathrm{CO}$ e $\mathrm{C} 1)$ em todos os corpos de prova estudados, nos levando a acreditar que a proximidade do intermediário do ponto de aplicação da força promova uma maior tensão por compressão do mesmo, o que torna imprescindível uma avaliação criteriosa do implante adjacente à extremidade livre, no que diz respeito ao suporte ósseo, para planejamento da extensão do cantilever ${ }^{41}$.

A aplicação de carga em uma infra-estrutura para prótese sobre implantes, segundo BENZING, GALL, WEBER ${ }^{3}$; produz uma energia de deformação no sistema que causa a flexão e deformação da infra-estrutura. Se uma grande quantidade de energia de deformação é consumida nos implantes próximos do ponto de aplicação da força, ocorre a redução da energia transmitida e baixa concentração de estresse nos demais implantes. Isto pode ser visualizado neste estudo, onde o implante adjacente à aplicação da força foi aquele que apresentou os maiores valores de deformação nas faces mesial e distal do intermediário ( $\mathrm{C} 0$ e $\mathrm{C} 1$ ).

A aplicação de uma carga estática de $100 \mathrm{~N}$ a $15 \mathrm{~mm}$ de distância do centro do implante adjacente à extremidade livre está de acordo com alguns autores $^{1}, 34,40,44,48,52,55,62$; SHACKLETON et al. ${ }^{46}$ os quais relatam que a extremidade livre de uma prótese fixa mandibular implanto-suportada pode variar de 15 a $20 \mathrm{~mm}$ de extensão devido a possibilidade de utilização de implantes mais longos na região entre forames mentonianos e em função da boa qualidade óssea da região.

Outro fator importante a salientar é a adaptação presente nos componentes da prótese, pois segundo RANGERT; JEMT; JÖRNEUS ${ }^{40}$, DUYCK; NAERT ${ }^{14}$ e $W E E^{57}$, a ausência de uma adaptação precisa da infraestrutura faz com que, enquanto alguns implantes recebem a maior carga, outros podem não sofrer carga alguma. De acordo com HECKER, ECKER ${ }^{21}$ a aplicação de forças cíclicas na região anterior de uma prótese fixa mandibular 
implanto-suportada promove a diminuição da desadaptação pelo assentamento da infra-estrutura, provavelmente em função da acomodação dos componentes da prótese frente à aplicação de uma força compressiva. Porém a aplicação de uma força na região de cantilever não provocou a diminuição da desadaptação, provavelmente devido à formação de um braço de alavanca com o fulcro situado no implante terminal, promovendo assim uma força que tende a rotacionar a infra-estrutura, sendo impedida pelos parafusos protéticos, provocando assim tração e compressão em diversas faces dos intermediários.

Esta situação é encontrada também neste estudo, onde a aplicação da força a $15 \mathrm{~mm}$ de distância do intermediário mais distal gerou compressão na região de fulcro (11) e variação de tração e compressão nos demais intermediários ( 12, 13, 14 e 15).

De acordo com os grupos analisados (G1 e G2), podemos observar que o tipo de liga utilizada na confecção das infra-estruturas influenciou no padrão de distribuição de tensões nos intermediários, de acordo com o demonstrado em vários estudos ${ }^{2,4,18,20,37 \text {, }}$

Devido ao menor módulo de elasticidade da liga de paládio-prata, em relação à de cobalto-cromo, e conseqüentemente por apresentar menor resistência à flexão, os resultados expressos nas tabelas 5.1 a 5.6 demonstram que os corpos de prova do grupo II apresentaram os menores valores de compressão registrada pelo canal 0 em relação aos corpos de prova do grupo I, o que nos faz acreditar que a liga de menor módulo de elasticidade se deformou mais, absorvendo a força aplicada na região de cantilever. Por outro lado a liga de maior módulo de elasticidade( $\mathrm{Co}-\mathrm{Cr}$ ) transmitiu mais intensamente a deformação ao intermediário terminal em relação ao grupo II como podemos observar nos gráficos 5.1 e 5.2 .

Para JACQUES ${ }^{25}$ a liga de baixo módulo de elasticidade por apresentar maior deformação e absorção das forças aplicadas, pode estar sujeita a fadiga, sobrecarregando os parafusos de fixação da prótese.

Segundo DUYCK, NAERT ${ }^{15}$, GENG, TAN, LIU ${ }^{16}$; BENZING, GALL, WEBER ${ }^{3}$ e WILLIAMS et al ${ }^{60}$, um material com menor módulo de 
elasticidade oferece menor resistência à flexão; uma infra-estrutura confeccionada com liga de metal básico, mais rígida, sofre menor deformação, sendo menos sujeita a fadiga e conseqüentemente não sobrecarregando os parafusos. Por isso recomendam o emprego de ligas com alto módulo de elasticidade para próteses implanto-suportadas.

Dentre as ligas com alto módulo de elasticidade, destaca-se a liga de cobalto-cromo que é utilizada neste estudo, pois apresenta características físicas, químicas e biologicamente favoráveis ${ }^{11,10,17,24,25,30,33}$.

Como podemos visualizar nos gráficos das deformações sofridas por cada corpo de prova individualmente (figuras de 5.3 a 5.8), tanto nos corpos de prova do grupo I como do grupo II, o aumento da altura do intermediário promoveu um aumento da deformação por compressão nos canais situados no intermediário adjacente ao cantilever (C0 e C1), principalmente na superfície distal (C0).

\section{Deformação $\operatorname{CoCr}(4,0 \mathrm{~mm})$}

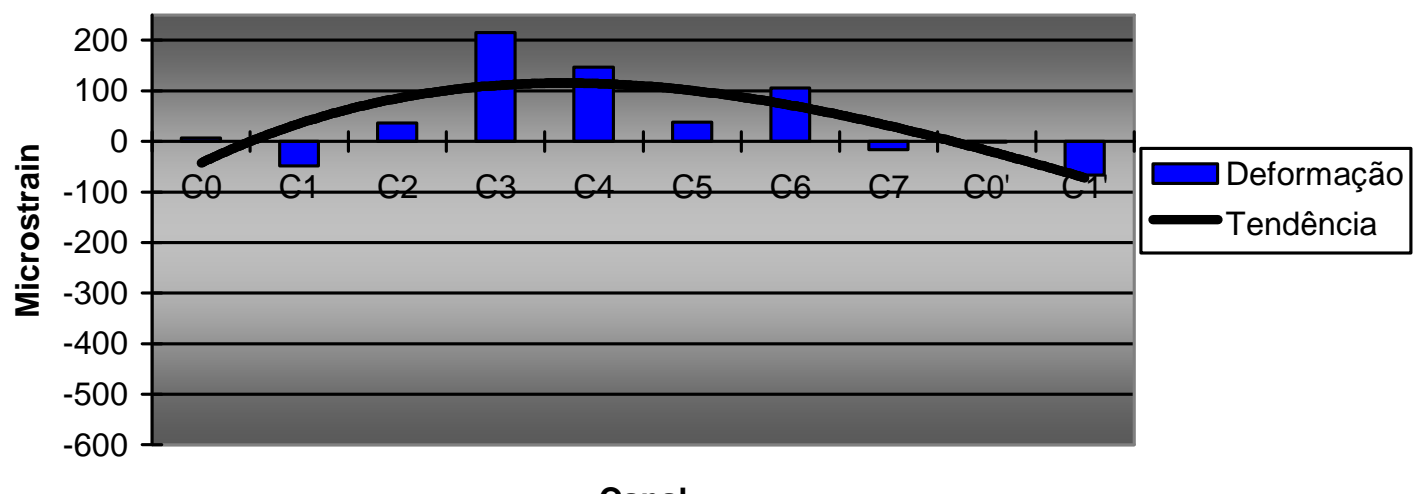

Canal

Figura 5.3. Gráfico das médias de microdeformações sofridas pelo corpo de prova I, apresentando a tendência a deformação da infra-estrutura de CoCr, com intermediários de $4,0 \mathrm{~mm}$ de altura. 


\section{Deformação $\operatorname{CoCr}(5,5 \mathrm{~mm})$}

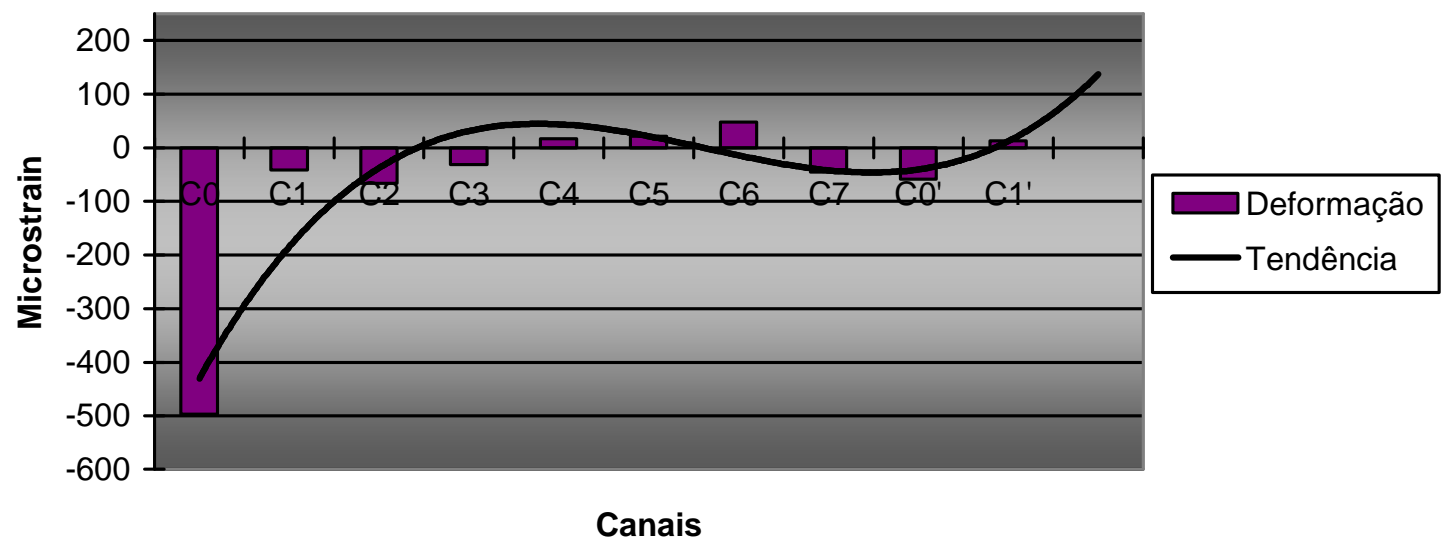

Figura 5.4. Gráfico das médias de microdeformações sofridas pelo corpo de prova II, apresentando a tendência a deformação da infra-estrutura de CoCr, com intermediários de $5,5 \mathrm{~mm}$ de altura.

\section{Deformação $\operatorname{CoCr}(7,0$ mm)}

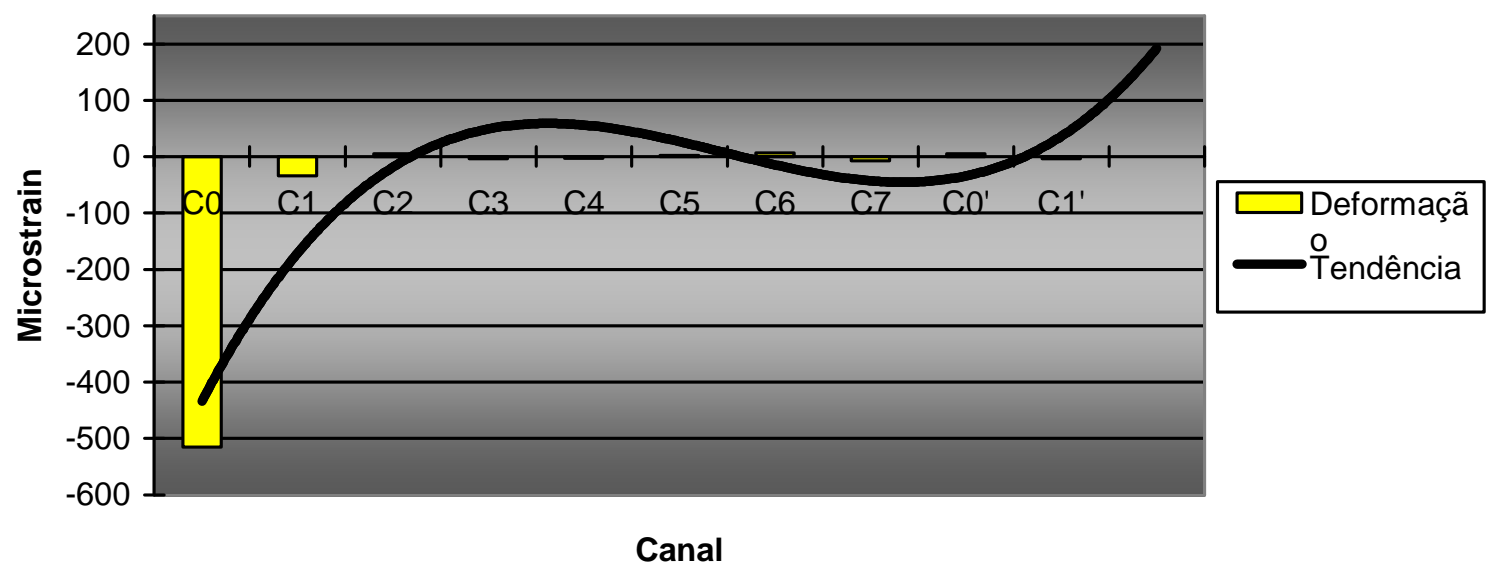

Figura 5.5. Gráfico das médias de microdeformações sofridas pelo corpo de prova III, apresentando a tendência a deformação da infra-estrutura de CoCr, com intermediários de 7,0 mm de altura. 


\section{Deformação PdAg (4,0 mm)}

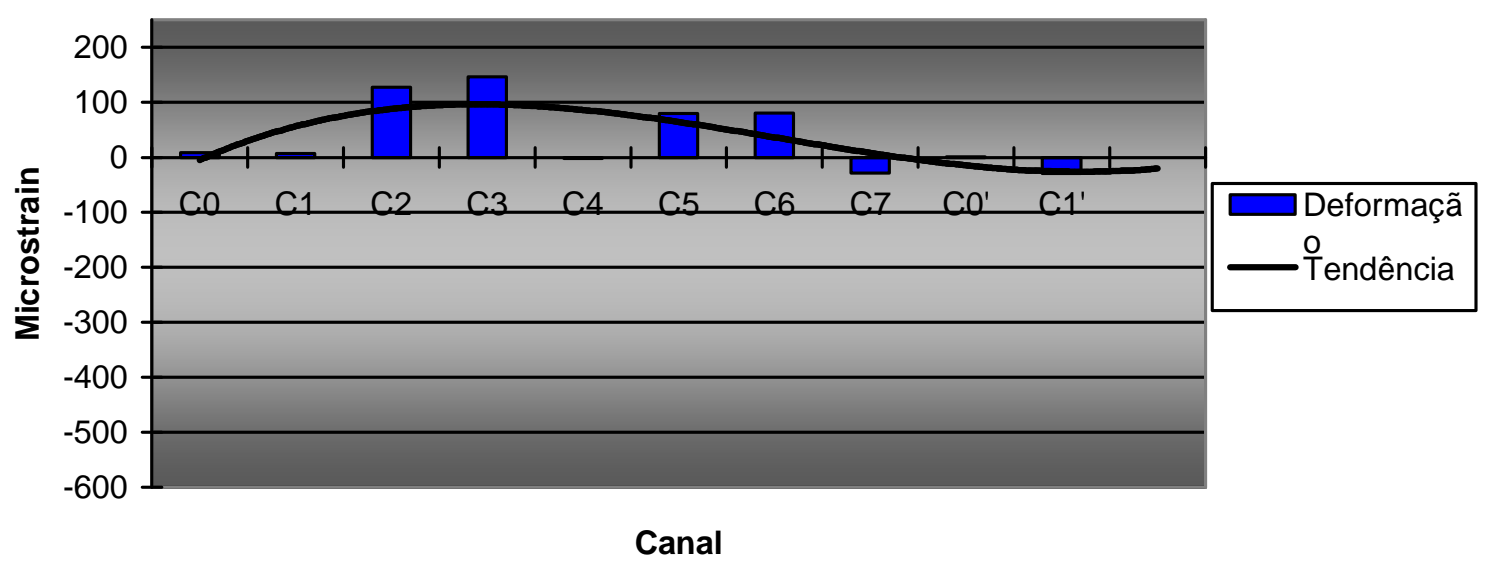

Figura 5.6. Gráfico das médias de microdeformações sofridas pelo corpo de prova IV, apresentando a tendência a deformação da infra-estrutura de PdAg, com intermediários de 4,0 $\mathrm{mm}$ de altura.

\section{Deformação PdAg (5,5 mm)}

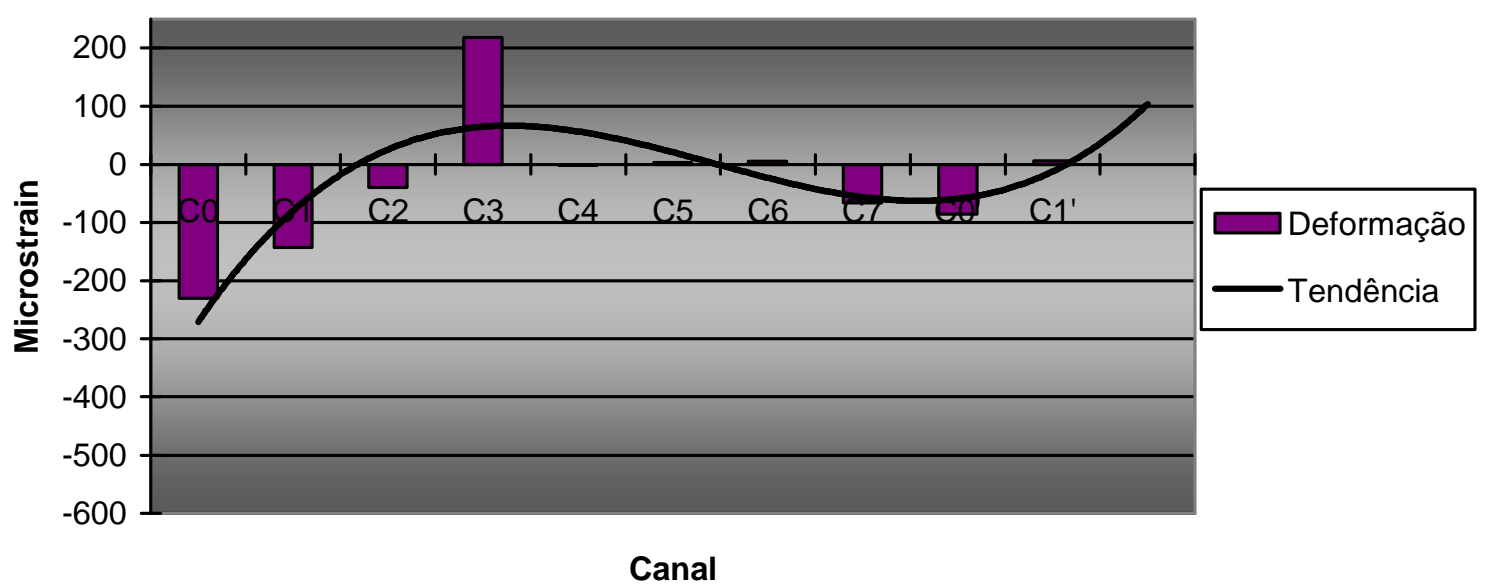

Figura 5.7 - Gráfico das médias de microdeformações sofridas pelo corpo de prova $V$, apresentando a tendência a deformação da infra-estrutura de PdAg, com intermediários de $5,5 \mathrm{~mm}$ de altura. 


\section{Deformação PdAg (7,0 mm)}

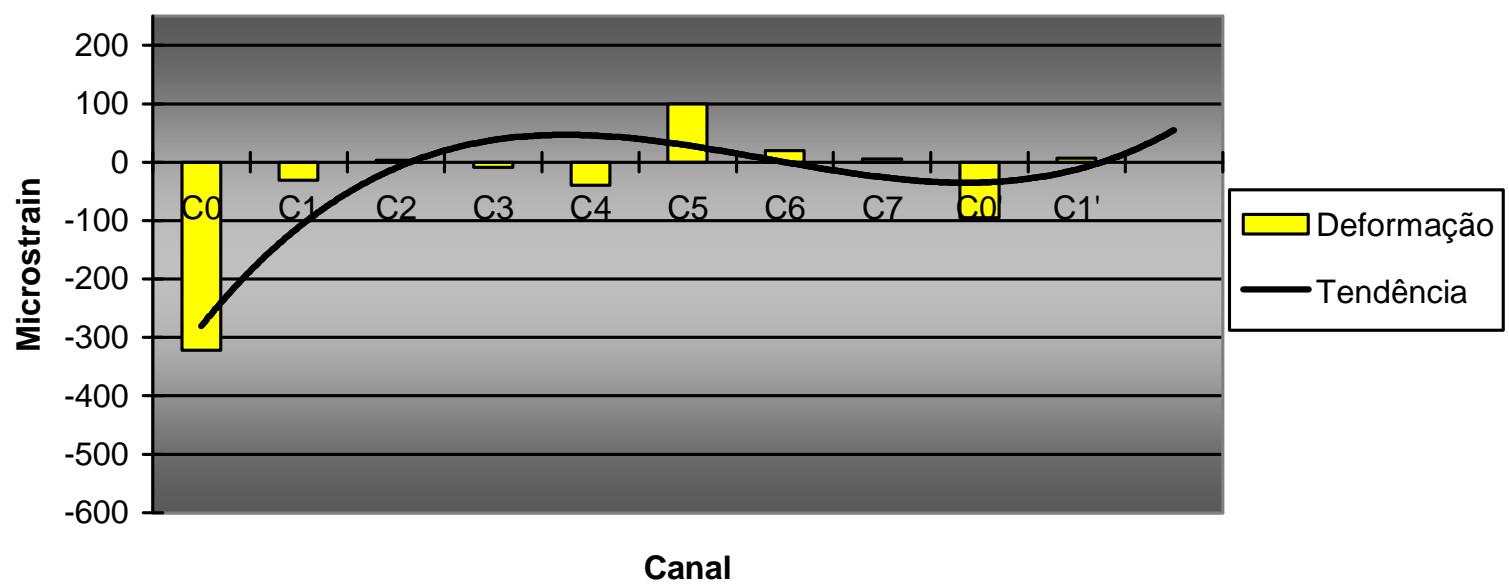

Figura 5.8. Gráfico das médias de microdeformações sofridas pelo corpo de prova VI, apresentando a tendência a deformação da infra-estrutura de PdAg, com intermediários de 7,0 mm de altura.

Os valores de microdeformação do canal 0 do grupo I são, respectivamente, de $7,490 \mu \varepsilon ;-496,959 \mu \varepsilon$ e $-514,819 \mu \varepsilon$ para os intermediários de $4,0 \mathrm{~mm} ; 5,5 \mathrm{~mm}$ e $7,0 \mathrm{~mm}$ de altura. Enquanto que para o grupo II os valores obtidos para o canal 0 (C0) são de 8,490 $\mu \varepsilon ;-230,677 \mu \varepsilon$ e -322,250 $\mu \varepsilon$ para os intermediários de 4,0 mm; 5,5 mm e 7,0 mm de altura, como observado nas tabelas de 2 a 7 .

Devido a estes resultados podemos dizer que o aumento da altura do intermediário promoveu um aumento da microdeformação captada pelos extensômetros lineares elétricos no intermediário (11) adjacente ao cantilever $(15 \mathrm{~mm})$ que recebeu a aplicação da força de $100 \mathrm{~N}$. Esse aumento da microdeformação foi promovido pelo aumento da distância entre a base do componente protético da infra-estrutura e a cabeça do implante. Com isso, aumenta também o braço de alavanca entre o ponto de aplicação da força e o implante.

Nas figuras 5.3 a 5.8 o comportamento da barra sobre os intermediários pode ser expresso pela tendência à deformação, obtida com 
base nas leituras realizadas pelos canais posicionados nos intermediários 11 , I2, I3, 14 e 15.

Os valores numéricos expressos em tração e compressão, são resultados do comportamento da barra frente a aplicação da força, onde o módulo de elasticidade da liga influencia no tipo de deformação sofrida pela barra e conseqüentemente nas tensões transmitidas aos intermediários.

Considerando hipoteticamente uma barra idealmente elástica e reta, com módulo de elasticidade próximo de zero, a deformação sofrida por esta barra frente a aplicação de uma força se aproximaria do desenho do gráfico de tendência. Esta curva nos da a tendência a deformação da região entre os pontos onde estão posicionados os extensômetros do mesmo intermediário e também entre os pontos onde estão posicionados os extensômetros nos intermediários vizinhos, nos dando assim uma linha contínua de deformação, tendo como base as deformações dos intermediários. Porém, devido ao formato da barra em forma de ferradura e ao fato desta não ser perfeitamente elástica, há uma tendência a rotação durante a aplicação da força, a qual é impedida pelos parafusos protéticos que fixam a barra aos intermediários. Assim os gráficos obtidos não apresentam um padrão definido de tração e compressão, o que dificulta a interpretação dos dados. A utilização do gráfico de tendência visa facilitar a compreensão do comportamento dos corpos de prova.

Observamos no presente estudo que, de acordo com os resultados obtidos, o intermediário adjacente ao cantilever sofreu a maior deformação por compressão captada pelos canais de extensometria, que o tipo de liga utilizada na confecção das infra-estruturas influencia no padrão de deformação sofrido pelos intermediários e que a variação da altura dos intermediários promove o aumento da deformação por compressão captada pelos canais de extensometria no implante adjacente ao lado da aplicação da força, devido ao aumento do braço de alavanca. 
CONCLUSÕES 


\section{7 - CONCLUSÕES}

A proposição deste experimento foi avaliar a deformação gerada em diferentes alturas de componentes intermediários de prótese fixa implantosuportada. Extensômetros lineares elétricos foram utilizados para medir a deformação dos intermediários gerada frente a aplicação de uma carga estática de $100 \mathrm{~N}$ em um cantilever de $15 \mathrm{~mm}$.

Diante dos resultados obtidos, pode-se concluir que:

1. O aumento da altura dos intermediários promoveu o aumento da deformação por compressão no implante adjacente ao lado da aplicação da carga, devido ao aumento do braço de alavanca.

2. A infra-estrutura confeccionada em liga de $\mathrm{CoCr}$, promoveu maior deformação por compressão no intermediário adjacente ao lado da aplicação da carga quando comparada com a de PdAg. 
REFERÊNCIAS BIBLIOGRÁFICAS 


\section{REFERÊNCIAS BIBLIOGRÁFICAS ${ }^{*}$}

1. ADELL, R. et al. A 15-year study of osseointegrated implants in the treatment of the edentulous jaw. Int. J. oral Surg., v.10, n.6, p.387-416, Dec. 1981.

2. AKÇA, K; ÇERELI, M.C.; IPLIKÇIOGLU, H. A comparison of three-dimensional finite element stress analysis with in vitro strain gauge measurements on dental implants. Int. J. Prosthodont., v.15, n.2, p.115-21, 2002.

3. BENZING, U.R.; GALL, H.; WEBER, H. Biomechanical aspects of two different implant-prosthetic concepts for edentulous maxillae. Int. J. oral Maxillofac. Implants, v.10, n.5, p.188-98, Sep/Oct 1995.

4. BOUCHART, I.G.; ZARO, M.A. Extensômetros de resistência elétrica (strain gauges) - princípios de operação e utilização em transdutores. Porto Alegre, Ed. da Universidade UFRGS, 55p;1982.

5. CARLSON, B.; CARLSON, G.E. Prosthodontic complications in osseointegrated dental implant tratment. Int. J. oral Maxillofac. Implants, v.9, n.1, p.90-4, Jan/Feb. 1994.

6. CARR, A.B.; BRUNSKI, J.B.; HURLEY, E. Effects of fabrication, finishing end polishing on preload in prosteses using conventional gold and plastic cylinders. Int. J. oral Maxillofac. Implants, v.11, n.5, Sep/Oct., p.589-9, 1996.

7. CHAO, Y. et al. A study into the use of chromium-cobalt alloy for constructing the framework for osseointegrated prostheses. Clin. Materials, v. 3, p. 309-15, 1988.

"Normas recomendadas para uso no âmbito da Universidade de São Paulo, com base no documento "Referências Bibliográficas: exemplos", emanado do Conselho Supervisor do Sistema Integrado de Bibliotecas da USP, em reunião de 20 de setembro de 1990. 
8. CLELLAND, N.L. et al. A photoelastic and strain gauge analysis of angled abutments for na implant system. Int. J. oral Maxillofac. Implants, v.8, n.5, p.541-8, 1993.

9. CLELLAND, N.L.; MEADE, C.V.P. Comparison of strains produced in a bone simulant between conventional cast and resin-luted implant frameworks. Int. J. oral Maxillofac. Implants, v.12, n.6, p. 793-99, 1997.

10. Concil on Dental Materials, Instruments and Equipment. Report on base metal alloys for crown and briidge application: benefits and risks. J. Amer. dent. Assoc., v. 111, n. 3, p. 479-83, Sept. 1985.

11. Council on Dental Materials, Instruments and Equipment. (National Institute of Dental Research) Workshop: biocompatibility of metals in dentistry. J. Amer. dent. Assoc., v.109, n.3, p.469-71, Sept. 1984.

12. CRAIG, R.G.; O' BRIEN, W.J.; POWERS, J.M. Dental Materials - Properties and manipulation. 6 ed. St. Louis, Mosby, 1996. .

13. DAVIS, D.M. ; ZARB, G.A. ; CHAO Y. Studies on frameworks for osseointegrated prostheses: Part 1. The effect of varying the number of supporting abutments. Int. J. Oral Maxillofac. Implants, v. 3, n. 3, p. 197201, Fall 1988.

14. DUYCK et al. Pre-load on oralimplantsafter screw thightening fixed full prostheses: na in vivo study. J. Oral Rehab., v.28, n.3 March, , p.226-233, 2001.

15. DUYCK, J.; NAERT, I. Influence of prothesis fit and effect of a luting system on the prosthetic connection preload: na in vitro study. Int. J. Prosthodont. v.15, n.4, p.389-96, 2002. Y11

16. GENG, J.P; TAN, K.B.; LIU, G.R. Application of finite element analysis in implant dentistry: a review of the literature. J. prosthet. Dent., v.85, n.6, p. 585-98, June 2001. 
17. GIL, F.J. et al. In vitro corrosion behaviour and metallic ion release of different prosthodontic alloys. Int. dent. J. v.49, n.6, p.361-67, 1999.

18. GOLL, G E. Production of accuratelly fitting full-arch implant frameworks: part I - clinical proceduures. J. prosthet. Dent., v. 66, n. 3, p. 377-84, Sept. 1991.

19. GOODACRE, C J, et all.Clinical complications with implant and implant prostheses. J prosthet Dent, v. 90, n. 2, p. 121-32, 2003.

20. GOODACRE, C.J.; KAN, J.Y.K.; RUNGCHARASSAEN, G.K. Clinical complications of osseointegrated implants. J. prosthet. Dent., v.81, n.5, p.533-52, 1999.

21. HECKER, D M; ECKER, S, E. Cyclic loading of implant-supported prostheses: Changes in component fit over time. J prosthet Dent, v. 89, n. 4, p. 34651, 2003.

22. HOBKIRK, J.A; HANTHOULAS, T.K. The influence of mandibular deformation implant numbers and loading position on detected forces in abutment supporting fixed implant superstructures. J. prosth. Dent., v.80, n.2, p.164-74, 1998.

23. HULTERSTRÖM, M.; NILSSON, U. Cobalt-chromium as a framework material in implant-supported fixed prostheses: A 3-year follow-up. Int. J. oral Maxillofac. Implants, v. 9, n. 4, p. 449-54, 1994.

24. ISA, Z. M.; HOBKIRK, J. A. The effects of superstructure fit and loading on individual implant units: part I. the effects of tightening the gold screws and placement of a superstructure with varying degrees of fit. Eur. J.

Prosthodont. Restorat. Dent., v. 3, n. 6, p. 247-53, 1995.

\section{JACQUES, L. B. Análise do estresse gerado em componentes de prótese} fixa implanto-suportada, através do uso de extensômetros. Bauru, 2000. 71p. Dissertação (Mestrado) - Faculdade de Odontologia de Bauru, Universidade de São Paulo.

26. JEMT, T et al. In vivo load measurements on osseointegrated implants 
supporting fixed or removable prostheses: a comparative pilot study. Int. J. oral Maxillofac. Implants, v.6, n.4, Winter, 1991, p.413-17.

27. JEMT, T. Failures and complications in 391 consecutively inserted fixed prostheses supported by branemark implants in edentulous jaws: a study of treatment form the time of prosthesis placement to the first annual checkup. Int. J. oral Maxillofac. Implants, v.6, n.3, p.270-6, 1991.

28. JORNÉUS, L.; JEMT, T.; CARLSSON, L. Loads and design of screw joints for single crowns supported by osseointegrated implants. Int. J. oral Maxillofac. Implants. v.7, n.3, p.353-9, 1992.

29. KANO, S.C. Disajustment of prosthetic components using different alloys. J. dent. Res., v.74, n.3, p.806, 1995./ Abstract n.206/.

30. KANSU, G.; AYDIN, A.K. Evaluation of the biocompatibility of various dental alloys: part 1- toxic potentials. Europ J. Prosthodont. Restorat. Dent. v.4, n.3, Dec., p.155-61, 1996.

31. KORIOTH, T.W.P.; JOHANN,A.R. Influence of mandibular superstructure shape on implant stresses during simulated posterior biting. J. prosthet.

Dent. v.89, n.1, p.67-72, 1999.

32. HOLLWEG, H. Análise da passividade de adaptação de infra-estruuras para prótese fixa implanto-suportada, através do uso de extensômetros. Bauru, 2000. 71p, Dissertação (Doutorado) - Faculdade de Odontologia de Bauru, Universidade de São Paulo.

33. LEINFELDER, K.F. An evaluation of casting alloys used for restorative procedures. J. Amer. dent. Assoc., v.128, Ja 1997.

34. LINDQUIST, L. W.; CARLSSON, G. E. Maxillary fixed prostheses on osseointegrated dental implants. J. prosthet. Dent., v. 50, n. 2, p. 262-70, Aug. 1983.

35. MENDES, E. N. C. Avaliação da adaptação passiva de infra-estruturas 
sobre implantes, antes e após soldagem, em função da deformação dos intermediários medida com extensômetros lineares elétricos.

Bauru, 2003. 145p. Dissertação (Mestrado) - Faculdade de Odontologia de Bauru, Universidade de São Paulo.

36. MILLINGTON, N.D.; LEUNG, T. Inaccurate fit of implant superstructures. Part 1: stresses generated on the superstructure relative to the size of fit discrepancy. Int. J. Prosthodont., v.8, n.6, p.511-16, 1995.

37. MILLINGTON, N.D.; LEUNG, T. Stress on an implant superstructure in relation to its accuracy of fit. J. dent. Res., v.71, p.529, 1992. /Abstract n.108/.

38. PAPAVASILIOU, G.; KAMPOSIORA, P.; FELTON, D.A . 3D-FEA of ossointegration percentages and patterns on implants-bone interfacial estresses. J. Dent. v.25, n.6, p.485-91, 1997.

39. PATTERSON, E.A. et al. Distribution of load in an oral prosthesis system: an in vitro study. Int. J. oral Maxillofac. Implants, v. 10, n. 5, p. 552-60, Sep./Oct. 1995.

40. RANGERT, B.; JEMT, T.; JÖRNEUS, L. Forces and moments on Brånemark Implants. Int. J. Oral Maxillofac. Implants, v. 4, n. 3, p. 241-7, Fall 1989.

41. RUBO, J. et al. Finit element analysis of stress distribution on dental implants: a study of seven clinical variables. Part I - stresses on implants, abutments and frameworks. Int. J. Prostodont., v. 12, n. 6, p. 567, Nov./Dec. 1999. /Abstract/.

42. SAHIN, $S$ et all. The influence of functional forces on the biomechanics of implant-suported prostheses - a review. J. Dent., v. 30, p. 271-282, 2002.

43. SAHIN, S; ÇEHRELI, M.C. The significance of passive framework fit in implant prosthodontics: current status. J. Implant Dent., v.10, n.2, p. 85-90, 2001.

44. SERGOZ, A; GUVENER, S. Finite element analysis of the effect of cantilever 
and implant length on stress distribution in na implant-supported fixed prostheses. J. prosthet. Dent., v. 76, n. 2, p. 165-9, Aug, 1996.

45. SERTGÖZ, A. Finite element analysis study of the effect of superstructure material on stress distribution in an implant-supported fixed prosthesis. Int. J. Prosthodont., v. 10, n. 1, p. 19-27, Jan./Feb. 1997.

46. SHACKLETON, J. et al. Prosthodontic complications and problems of fixturesupported prostheses. J. dent. Res., v. 71, n. 4, p. 1113, Apr. 1992. /Abstract n. 89/.

47. SKALAK, R. Biomechanical considerations in osseointegrated prostheses. J. prosth. Dent., v. 49, n. 6, p. 843-8, June 1983.

48. SPIEKERMANN, H. et al. Biomechanics. In: Color Atlas of Dental Medicine Implantology. New York, Thieme Medical Publishers, p. 81-9, 1995.

49. STEGAROIU, R; KHRAISAT, A; NOMURA, S E MIYAKAWA, O. Influence of superstructure materials on strain around an implant under 2 loading conditions: a technical investigation. Int J Oral Maxilifac Implants, v.19, n. 5, p. 735-42, 2004.

50. TAM, L.Y. et al. Comparison of marginal fit between cemented and cast implant frameworks. J. Dent. Res., v. 78, p. 328, 1999. /Abstract n. 1781/.

51. TAN, K.B. et al. Three-dimensional analysis of the casting accuracy of onepiece, osseointegrated implant-retained prostheses. Int. J. Prosth., v.6, n. 4, p.346-63, July/Aug. 1993.

52. TAYLOR, T. D. Fixed implant rehabilitation for the edentulous maxilla. Int. J. Oral Maxilofac. Implants. V. 6, n.3, p. 329-37, 1991.

53. TAYLOR, T.D. Prosthodontic problems and limitations associated with osseointegration. J prosthet Dent, v. 79, n. 1, p. 74-8, 1998.

54. TAYLOR, T.D.; AGAR, J.R. Twenty years of progress in implant 
prosthodontics. J. prosth. Dent., v.88, n.1, p. 89-95, July 2002.

55. VAN ZYL et al. Three-dimensional finite element model of a human mandible incorporating six osseointegrted implants for stress analysis of mandibular cantilever prostheses. Int. J. Oral Maxilofac. Implants, v. 10, n. 1, p. 51-7, Jan/Fev. 1995.

56. WASKERICZ. G. A.; OSTROWSKY, J. S.; PARKS, V. J. Photoelastic analysis of stress distribution transmitted from a fixed prosthesis attached to osseointegrated implants. Int. J oral Maxillofac. Implants, v. 9, n. 4, p. 405-11, 1994.

57. WEE, A. G. Comparisson of impression materials for direct multi-implant impressions. J. prosth. Dent., v.83, n.3, p.323-31, 2000.

58. WEINBERG, L.A. The biomechanics of force distribuition in implant-supported prostheses. Int. J. oral Maxillofac. Implants, v.8, n.1, p.19-31, 1993.

59. WEINER, S; EHRENBERG, D; LEHRMANN, N; SIMON, B; ZOHN,H. Sensory responses from loading of implants: a pilot study. Int J Oral Maxilofac Implants, v. 19, n. 1, p. 44-51, 2004.

60. WILLIAMS et al. Finite element analysis of fixed prosthesis attached to osseointegrated implants. Quintessence Int., v. 21, n.7, p. 563-70, July 1990.

61. YANASE, R.T. How do you test a cast framework fit for a full-arch fixed implantsupported prosthesis. Int. J. oral Maxillofac. Implants, v.9, n.4, p.170-4, 1994.

62.ZARB. G.A.; SCHMITT, A. The longitudinal clinical effectiveness of osseointegrated dental implants: the Toronto study. Part II: the prosthetic results. J. prosth. Dent., v. 64, n. 1, p. 53-61, Aug. 1990. 
ABSTRACT 


\section{ABSTRACT}

\section{ASSESSMENT OF THE DEFORMATION GENERATED IN DIFFERENT HEIGTS OF ABUTMENTS OF MANDIBULAR IMPLANT-SUPPORTED PROSTHESIS, WITH THE USE OF STRAIN GAUGES.}

In implant-supported prosthesis the different heights of abutments represent different lever arms to which the implants are submitted, leading to a deformation of the components that is not completely understood. The objective of this study was to assess the deformation ocurring in different heights of abutments of mandibular implant-supported fixed prosthesis. A circular master cast made of steel (Steel 1010/20) was used with five perforations containing implant replicas of $3,75 \mathrm{~mm}$ of diameter in which the abutments were seated. The specimens were divided in two groups of three specimens each, according to the type of alloy of the framework $(\mathrm{CoCr}$ or $\mathrm{PdAg}$ ) and the abutment's height $(4,0 \mathrm{~mm}, 5,5 \mathrm{~mm}$ and $7,0 \mathrm{~mm})$, respectively. A force of $100 \mathrm{~N}$ was applied at a point $15 \mathrm{~mm}$ distal to the center of the terminal abutment. Readings of the deformations generated on the mesial and distal aspects of the abutment were obtained with the use of strain gages. The results of this study demonstrated that the deformation observed in the abutments adjacent to the cantilever arm is proportional to the increase of the abutment's height and elastic modulous of the alloy.

Keywords: Dental prosthesis, implant-supported. Biomechanics. Dental Implantation. 